\title{
Plasticity in Developing Brain: Active Auditory Exposure Impacts Prelinguistic Acoustic Mapping
}

\author{
April A. Benasich, ${ }^{1}$ Naseem A. Choudhury, ${ }^{1,2}$ Teresa Realpe-Bonilla, ${ }^{1}$ and Cynthia P. Roesler ${ }^{1}$ \\ ${ }^{1}$ Center for Molecular and Behavioral Neuroscience, Rutgers, The State University of New Jersey-Newark, Newark, New Jersey 07102 , and ${ }^{2}$ Department of \\ Psychology, School of Social Science and Human Services, Ramapo College of New Jersey, Mahwah, New Jersey 07430
}

\begin{abstract}
A major task across infancy is the creation and tuning of the acoustic maps that allow efficient native language processing. This process crucially depends on ongoing neural plasticity and keen sensitivity to environmental cues. Development of sensory mapping has been widely studied in animal models, demonstrating that cortical representations of the sensory environment are continuously modified by experience. One critical period for optimizing human language mapping is early in the first year; however, the neural processes involved and the influence of passive compared with active experience are as yet incompletely understood. Here we demonstrate that, while both active and passive acoustic experience from 4 to 7 months of age, using temporally modulated nonspeech stimuli, impacts acoustic mapping, active experience confers a significant advantage. Using event-related potentials (ERPs), we show that active experience increases perceptual vigilance/attention to environmental acoustic stimuli (e.g., larger and faster P2 peaks) when compared with passive experience or maturation alone. Faster latencies are also seen for the change discrimination peak (N2*) that has been shown to be a robust infant predictor of later language through age 4 years. Sharpening is evident for both trained and untrained stimuli over and above that seen for maturation alone. Effects were also seen on ERP morphology for the active experience group with development of more complex waveforms more often seen in typically developing 12- to 24-month-old children. The promise of selectively "fine-tuning" acoustic mapping as it emerges has far-reaching implications for the amelioration and/or prevention of developmental language disorders.
\end{abstract}

Key words: acoustic mapping; developmental plasticity; EEG/ERP; human infant; prelinguistic; training

\section{Introduction}

The foundations of language are established in infancy and can be observed well before spoken language emerges. Specifically, finegrained analyses in the tens-of-milliseconds range appear to be critical to decoding the speech stream (Eilers et al., 1981; Aslin, 1989; Werker and Tees, 2005). To facilitate decoding, the developing brain constructs acoustic maps of the sounds of its native language, thus allowing the child to respond in a fast automatic way to incoming language (Kuhl et al., 1992; Werker and Tees, 2005). This process crucially depends on ongoing neural plasticity and the exquisite sensitivity to environmental cues that characterize early brain development (deVillers-Sidani et al., 2007; Kuhl, 2010; Froemke and Jones, 2011).

The processes involved in exposure-based plasticity are complex and incompletely understood in human infants, although animal studies demonstrate that developing cortex is highly plastic with experience (Kilgard et al., 2001; Zhang et al., 2001; Ranasinghe et al., 2012). In developing rats, "patterned auditory

\footnotetext{
Received March 11, 2014; revised Aug. 14, 2014; accepted Aug. 20, 2014.

Author contributions: A.A.B. and N.A.C. designed research;N.A.C., T.R.-B., and C.P.R. performed research; A.A.B., N.A.C., and T.R.-B. analyzed data; A.A.B., N.A.C., and C.P.R. wrote the paper.

This research was supported by the Elizabeth $\mathrm{H}$. Solomon Center for Neurodevelopmental Research with additional funding from a Rutgers University Board of Trustees Excellence in Research Award to A.A.B.

The authors declare no competing financial interests.

Correspondence should be addressed to April A. Benasich, Center for Molecular and Behavioral Neuroscience, Rutgers, The State University of New Jersey-Newark, Newark, NJ 07102.E-mail: benasich@andromeda.rutgers.edu. DOI:10.1523/JNEUROSCI.0972-14.2014

Copyright $\odot 2014$ the authors $\quad 0270-6474 / 14 / 3413349-15 \$ 15.00 / 0$
}

inputs play a crucial role in shaping neuronal processing/decoding circuits in primary auditory cortex" (Zhang et al., 2002); moreover, response latency of cortical neurons changes as a function of sensory experience (Moucha et al., 2005). Threlkeld et al. (2009) demonstrated in rats that for both simple tones and complex auditory discriminations, prior early experience significantly improved acoustic discrimination as adults. For human infants, it is probable that emergent selective representation of the phonemic structure of the infant's native language is a manifestation of this powerful, sound exposure-based plasticity (Kuhl et al., 1992), and thus facilitates accurate construction of early acoustic maps (Guenther and Gjaja, 1996).

A number of studies have manipulated infants' sound environments, introducing novel speech (Kuhl et al., 2003) or contrasting vowel sounds (Cheour et al., 2002), and then assessed discrimination. One study more systematically manipulated auditory exposure observing specific effects on acoustic mapping. Four-month-old children received a week of daily passive experience (PEx) with differing musical timbres; plastic changes in electroencephalograms (EEGs)/event-related potential (ERPs) were differentially induced in acoustic representations (Trainor et al., 2011). The authors concluded that "exposure to a particular timbre in infancy enhances representations, leading to more precise pitch processing for that timbre." However, to date, no infant study has determined whether interactive experience, using nonspeech-containing linguistically relevant cues, would impact and perhaps optimize the cortical representations that will ultimately 

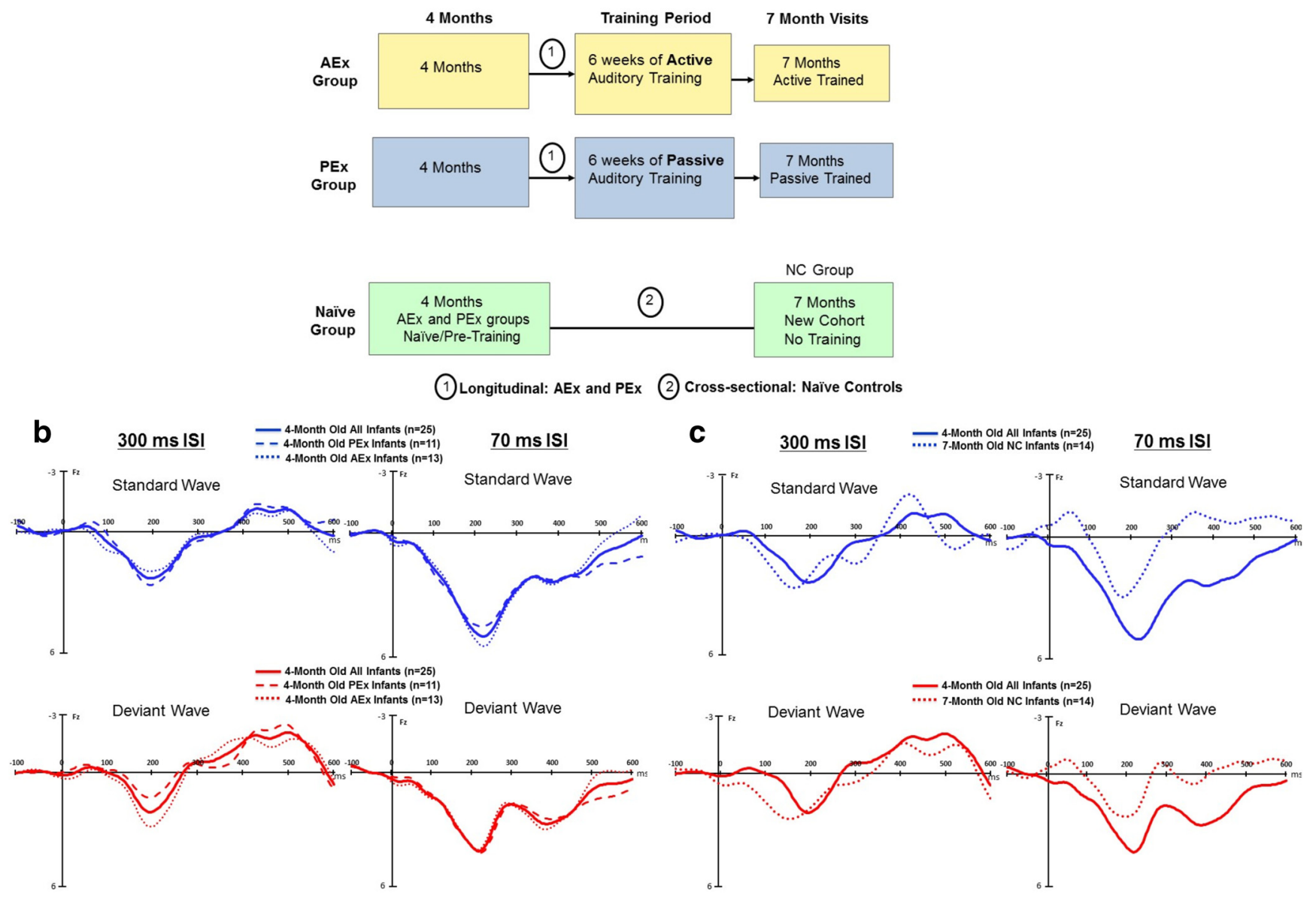

Figure 1. Overall study design and grand average waveforms depicting maturational effects from 4 to 7 months of age. $\boldsymbol{a}$, Schematic of overall study design. $\boldsymbol{b}$, Grand average waveforms from 124 electrodes at $F z$ at the initial 4 month visit (before auditory exposure) for the AEx and PEx groups, and for both 4 month groups combined. Stimuli were complex tone pairs; each tone was 70 ms in duration with either a 300 or $70 \mathrm{~ms}$ within-pair ISI, presented in a standard blocked design. Standard (blue) and deviant (red) waves are shown for the control ( $300 \mathrm{~ms} I S \mathrm{I})$ and fast-rate (70 ms ISI) conditions. No significant differences emerged between the AEx (dotted line) and PEx (dashed line) groups; thus, all the 4-month-old pre-exposure infants (solid line) combined served as the control group for the cross-sectional maturation analyses. c, Grand average waveforms from 124 electrodes at Fz, for the 300 and $70 \mathrm{~ms} \mathrm{ISI} \mathrm{conditions} \mathrm{for} \mathrm{the} 4$ month combined pre-exposure group and the 7 month NC group. Standard waves are in blue, and deviant waves are in red. Maturational effects were seen on morphology, amplitude, and latency as a function of age for both conditions on both standard and deviant waves at all (frontal, frontocentral, and central) channels. At $300 \mathrm{~ms} \mathrm{ISI,} \mathrm{significantly} \mathrm{faster} \mathrm{latencies} \mathrm{for} \mathrm{the} 7$ month group compared with the younger infants are seen for the P1 and P2 peaks as well as significantly larger amplitudes on the standard and deviant waves. Similarly, at $70 \mathrm{~ms} I \mathrm{SI}$ the P1 on the standard waves and the P1 and P2 on the deviant waves in 7-month-old children were significantly faster and smaller in amplitude than those in 4-month-old children. Negative peak amplitudes increased from 4 to 7 months.

support later language. Specifically, we ask whether "active engagement" that recruits attention to salient properties of the acoustic environment differs from passive exposure to the same sounds.

We used EEGs/ERPs to examine neural correlates of acoustic mapping before and after a 6 week interactive or passive acoustic experience delivered from 4 to 7 months. We hypothesized, based on the extant literature, that, in addition to expected maturational differences in latency and amplitude, a targeted, interactive acoustic experience would do the following: (1) induce more precise and efficient acoustic mapping; (2) show a differential rate effect such that stimuli with a faster rate would drive acoustic plasticity more than slower rates; (3) improve both processing speed and discrimination of trained stimuli; and (4) generalize to untrained stimuli as a consequence of more sharply defined acoustic maps.

\section{Materials and Methods}

Participants

Forty-nine infants were recruited and then randomly assigned to one of three groups. The study used a mixed longitudinal and cross- sectional design that ensured both within-age and within-subject control subjects (Fig. 1a). The active experience (AEx; $N=18 ; 10$ males) and PEx ( $N=17$; 9 males) groups were followed longitudinally from 4 to 7 months of age. For both groups, the mean (SD) age at pretest was 4.4 months ( 0.18 months $)$ and the mean age at post-test was 7.2 months (0.16 months). A naive control (NC) group $(N=14$; 7 males) was recruited at 7 months of age (mean age, 7.1 months; SD, 0.16 years) and served as the cross-sectional maturational control. Infants were recruited from urban and suburban communities from a large metropolitan area. All infants came from monolingual Englishspeaking families and were of middle to upper middle socioeconomic class. Parents reported uneventful prenatal and perinatal circumstances, and all infants were born healthy, at full term, and of normal birth weight. Exclusionary criteria included reports of family history of language-learning impairments, psychiatric disorders and/or autism; and infant history of hearing loss, repeated episodes of otitis media or other medical or neurological disorders. Parents were compensated for their time, and infants received a toy after the visit. The study was conducted in accordance with the Declaration of Helsinki, and informed consent, approved by the Institutional Review Board of our university, was obtained from all participants before study participation. 
Table 1. Time window ranges for peak extraction

\begin{tabular}{|c|c|c|c|c|c|c|}
\hline \multirow[b]{2}{*}{ Peak } & \multicolumn{2}{|l|}{ AEx group } & \multicolumn{2}{|l|}{ PEx group } & \multicolumn{2}{|c|}{ NC group } \\
\hline & Pretest & Post-test & Pretest & Post-test & Pretest & Post-test \\
\hline \multicolumn{7}{|c|}{300 ms ISI paradigm } \\
\hline $\mathrm{P} 1_{\mathrm{T} 1}$ & $140-210$ & $120-190$ & $160-230$ & $120-200$ & & $110-190$ \\
\hline $\mathrm{N} 1_{\mathrm{T} 1}$ & $240-300$ & $200-270$ & $240-320$ & $200-280$ & & $200-270$ \\
\hline $\mathrm{P}_{\mathrm{T} 1}$ & $300-370$ & $260-330$ & $320-370$ & $280-340$ & & $270-340$ \\
\hline $\mathrm{N} 2_{\mathrm{T} 1}$ & $380-450$ & $350-430$ & $370-430$ & $340-430$ & & $370-440$ \\
\hline $\mathrm{P} 1_{\mathrm{T} 2}$ & $430-470(60-100)$ & $430-540(60-170)$ & $430-500(60-130)$ & $430-530(60-160)$ & & $440-500(70-130)$ \\
\hline $\mathrm{N} 1 \mathrm{~T}_{2}$ & $470-540(100-170)$ & $540-600(170-230)$ & $500-560(130-190)$ & $530-620(160-250)$ & & $500-600(130-230)$ \\
\hline $\mathrm{P}_{\mathrm{T} 2}$ & $540-650(170-280)$ & $600-700(230-330)$ & $560-670(190-300)$ & $620-720(250-350)$ & & $600-730(230-360)$ \\
\hline $\mathrm{N} 2 \mathrm{~T}_{2}$ & $650-740(280-370)$ & $700-800(330-430)$ & $670-680(300-310)$ & $720-810(350-440)$ & & $730-830(360-460)$ \\
\hline \multicolumn{7}{|c|}{70 ms ISI paradigm ${ }^{a}$} \\
\hline P1 & $170-240$ & $130-220$ & $170-240$ & $120-220$ & & $130-220$ \\
\hline $\mathrm{N} 1 / \mathrm{N} 2^{*}$ & $260-340(120-200)$ & $220-360(80-220)$ & $270-370(130-230)$ & $220-420(80-280)$ & & $250-360(110-220)$ \\
\hline P2 & $340-430(200-290)$ & $290-470(150-330)$ & $370-430(230-290)$ & $420-510(280-370)$ & & $320-470(180-330)$ \\
\hline \multicolumn{7}{|c|}{ Multideviant paradigm } \\
\hline P1 & & $80-140$ & & $90-160$ & & $100-160$ \\
\hline N1 & & $150-220$ & & $160-230$ & & $170-230$ \\
\hline P2 & & $230-300$ & & $230-320$ & & $240-320$ \\
\hline N2 & & $350-440$ & & $320-440$ & & $360-460$ \\
\hline
\end{tabular}

Latencies reported here are absolute values (from zero); relative values (from the second tone of the tone pair) are reported in parentheses. The time window ranges include both STD and DEV waveforms.

${ }^{a}$ Negative peak labels N1/N2* refer to the standard wave (N1)/deviant wave (N2*) peaks, respectively.

\section{Measures}

Electroencephalography. Dense-array EEGs/ERPs to auditory stimuli were collected from all infants at 4 and/or 7 months of age.

EEG/ERP stimuli. Stimuli were 70-ms-long (5 ms rise time $/ 5 \mathrm{~ms}$ fall time) complex tones with 15 harmonics and a $6 \mathrm{~dB}$ roll-off per octave. They were presented at an intensity of $75 \mathrm{~dB}$ SPL free-field via loudspeakers to the left and right of the participant. At both pretest (4 months of age) and post-test (7 months of age), a single-deviant oddball paradigm was used. Standard (STD) stimuli, $800-800 \mathrm{~Hz}$ complex tone pairs (STD, 708 tokens; 85\%), were interspersed with deviant (DEV) stimuli, $800-1200 \mathrm{~Hz}$ complex tone pairs (125 tokens; 15\%). The stimuli were presented in a passive auditory oddball paradigm using a blocked design with interstimulus intervals (ISIs) of either 70 or $300 \mathrm{~ms}$. In all cases, the $70 \mathrm{~ms}$ ISI tone pairs (the temporally modulated condition) were presented first followed by a second block of $300 \mathrm{~ms}$ ISI stimuli (control condition). The onset-to-onset intertrial intervals (ITIs) were 915 and $1140 \mathrm{~ms}$, and the offset-to-onset ITIs were 705 and $700 \mathrm{~ms}$, for 70 and 300 ms ISI conditions, respectively. Stimuli were presented in a pseudorandomized order where 3-12 STDs were presented before each DEV pair.

At post-test ( 7 months), in addition to the single-deviant oddball paradigm, a multiple deviant oddball paradigm was presented. Here, the standard stimulus was an $800 \mathrm{~Hz}$ single complex tone (1455 tokens) interspersed with the following deviant stimuli (120 tokens for each stimulus): (1) a $1200 \mathrm{~Hz}$ single complex tone (frequency deviant); (2) an 800 $\mathrm{Hz}$ single complex tone that was shorter in duration, $30 \mathrm{~ms}$ instead of 70 ms (duration deviant); (3) an $800 \mathrm{~Hz}$ single complex tone with a $20 \mathrm{~ms}$ silent gap inserted in the middle of a $70 \mathrm{~ms}$ ISI total stimuli length (gap deviant); and (4) single complex sinusoidal up-sweep with linear modulation from 800 to $1200 \mathrm{~Hz}$ (sweep deviant). Due to poor signal-to-noise ratio (i.e., a smaller percentage of usable deviant trials), the sweep deviant was not analyzed and is not included in the results presented here. The onset-to-onset ITI was $930 \mathrm{~ms}$ for all conditions. Stimuli were presented in a pseudorandomized order where 3-12 STD stimuli were presented before each DEV stimulus.

EEG/ERP acquisition. EEG/ERP data were acquired across several sessions. All stimuli were presented using E-Prime software (Psychology Software Tools). Sounds were presented free field to infants via left and right speakers attached to opposite walls of a sound-attenuated and electrically shielded sound booth (Industrial Acoustics Company). Infants were seated on their caregiver's lap in a comfortable chair equidistant from each speaker. An experimenter engaged the infant with a silent puppet show or toys. Age-appropriate movies without sound were also presented via video monitor. EEG data were recorded from a 128channel geodesic sensor net using an EGI (Electric Geodesics) recording system. The vertex electrode was used as the on-line reference electrode. EEG was sampled at $250 \mathrm{~Hz}$ and bandpass filtered on-line at $0.1-100 \mathrm{~Hz}$. Impedances were maintained at $<50 \mathrm{k} \Omega$.

EEG/ERP data processing. EEG was filtered off-line with a bandpass of $1-15 \mathrm{~Hz}$; trials containing signals higher than $\pm 200 \mu \mathrm{V}$ were discarded. Eye movements were estimated from EEG data at the electrodes slightly above and lateral to both eyes. Remaining artifact-free trials were averaged by stimulus type (deviant or predeviant standard) for each block. Segment length was the same as each onset-to-onset ITI (as detailed above). In addition, a $100 \mathrm{~ms}$ prestimulus segment was included for baseline correction, and 0 was taken as the time of onset of the first tone (single oddball paradigm) in the tone pair or the first stimulus (multiple oddball paradigm). An average of 92 artifact-free predeviant standard and deviant EEG segments were used in each block for averaging ERPs (300 ms ISI condition: predeviant standard average, 92 segments; deviant average, 91 segments; 70 ms ISI condition: predeviant standard average, 93 segments; deviant average, 93 segments). For the multiple deviant oddball condition, an average of 353 artifact-free predeviant standards and 88 deviant EEG segments were used.

ERP peak extraction. Based on the channel reduction strategy described by Choudhury and Benasich (2011), nine channels were selected from the 128-channel EGI sensor array. Maximum peak amplitude and latency were extracted at frontal (F3, Fz, and F4), frontocentral (Fc3, Fcz, and $\mathrm{Fc} 4)$, and central (C3, Cz, and C4) channels. Peaks reported here were identified as a positive or negative deflection from baseline and were labeled according to their order of appearance (e.g., P1, N1, P2, and N2). The change discrimination peak $\left(\mathrm{N} 2^{*}\right)$ is defined as the latency of the negative peak for the deviant wave that indicates the beginning of the discrimination response (for further discussion, see Choudhury and Benasich, 2011). Latencies reported are absolute values ( 0 was taken as time of onset from the first tone). Please refer to Table 1 for time windows.

\section{Behavioral assessments}

AEx group-go/no-go operant conditioning protocol. Before AEx, a go/ no-go ( $\mathrm{G} / \mathrm{N}-\mathrm{G})$ looking task designed to assess each infant's ability to learn an association between an auditory stimulus and the onset of a video reward (Nawyn et al., 2007) was administered. Successful learning of the contingency was demonstrated when the infant directed his/her gaze to a "reward" video presented in a confined display area after the presentation of the conditioned auditory stimulus and before the onset of the reward.

Auditory stimuli. The auditory stimuli consisted of two pure tones (70 ms duration) with fundamental frequencies of either 800 or $1200 \mathrm{~Hz}$. Tones were presented in pairs of either $800-800 \mathrm{~Hz}$ (standard) or $800-$ 
$1200 \mathrm{~Hz}$ (deviant/target) via free-field speakers in a quiet testing room. The within-pair ISI varied from 300 to $40 \mathrm{~ms}$, depending on the phase of the $\mathrm{G} / \mathrm{N}-\mathrm{G}$ session (as described below). Infants were taught to discriminate target from standard on these simple tone pairs (STD, $800-800 \mathrm{~Hz}$; DEV, $800-1200 \mathrm{~Hz}$ ).

A $4 \mathrm{~s}$ video reward stimulus was selected from age-appropriate DVD stimuli and appeared in a defined screen area representing $25 \times 15^{\circ}$ of visual angle.

Procedure. There were the following three phases: familiarization, training, and criterion. During all phases, standard stimuli were repeatedly presented, interspersed with experimenter-initiated target stimuli paired with video reward presentations. Target (go) trials were initiated when infant receptivity was judged to be optimal by the experimenter. For familiarization, infants were noncontingently rewarded for up to 10 correct responses/turns to presentations of the target stimulus to condition the association between the novel stimulus and the reward. During the training phase, infants were conditioned to direct their gaze to a specified reward region on a computer screen in response to a go trial (i.e., a series of three successive targets). The reward video was initiated automatically when the infant looked toward the reward area at any point over the go trial window.

During familiarization and training, the between-pair ISI was $300 \mathrm{~ms}$ with a stimulus onset asynchrony of $1500 \mathrm{~ms}$. If the child did not respond during the go trial, the reward video was initiated to maintain the stimulus/reward contingency. The training phase ended when the child responded correctly to 3 of 5 successive go trials or when a total of 10 target trials were presented. The child then proceeded to criterion phase. The criterion phase used the same go stimuli $(800-1200 \mathrm{~Hz})$. However, 10 no-go trials (i.e., a standard tone pair; $800-800 \mathrm{~Hz}$ ) were interspersed among the 10 go trials. Successful completion of criterion phase required the infant to show four of five correct responses on two go and two no-go trials within a block of five successive trials. All 18 AEx infants (100\%) were able to learn the task at a $300 \mathrm{~ms}$ ISI and demonstrate contingency learning during the criterion phase of the go/no-go procedure, thus moving on to the active experience sessions.

Active experience protocol. The AEx group entered the active training period 1 week after completion of pretest sessions. Infants visited the laboratory once a week $(\sim 20 \mathrm{~min})$ for 6 consecutive weeks and were taught to discriminate target from standard on three different types of acoustic stimuli. The training aim was to support and optimize acoustic mapping and auditory discrimination of brief, successive spatiotemporal cues during a time period when the developing brain is maximally sensitive to environmental sensory experience. The task was designed to focus attention on salient information in these nonlinguistic stimuli that had relevance for subsequent linguistic mapping and to gradually entrain widening subsets of auditory neurons.

Stimuli for active experience protocol. Infants were trained to discriminate target from standard on three different types of acoustic stimuli, as follows: weeks 1 and 2, complex tones (STD, 800-800 Hz; DEV, 800$1200 \mathrm{~Hz}$ ); weeks 3 and 4, bandpass noise (STD: 400-1900 Hz and 400$1900 \mathrm{~Hz}$; DEV: $400-1900 \mathrm{~Hz}$ and $800-1900 \mathrm{~Hz}$ ); and weeks 5 and 6: simple sweeps STD: $1600-1200 \mathrm{~Hz}$ and $1600-1200 \mathrm{~Hz}$; DEV: $1600-1200$ $\mathrm{Hz}$ and $1200-1600 \mathrm{~Hz}$ ). These stimuli were presented at varying ISIs using an up-down staircase procedure (Trehub et al., 1986). A go/no-go operantly conditioned paradigm assessed whether the infants continued to respond contingently to the stimulus/reward association and apply it as the target became progressively more difficult to resolve.

Procedure for active experience. There were three phases that included familiarization, training, and baseline. Phases 1 and 2 were the same as the familiarization and training described above for the go/no-go procedure.

Phase 3, baseline, was similar to phase 2, except stimuli were presented in blocks of 10 trials with 5 no-go trials (i.e., a standard tone pair) interspersed among 5 go trials, and the between-tone ISI increased or decreased according to infant performance. The criterion for decreasing the ISI was achieved if the infant had four of five correct responses, including two correct go and two correct no-go trial responses. If the infant failed the criterion, the computer algorithm increased the ISI. The task continued in this fashion until the child fatigued ( $~ 7-9 \mathrm{~min})$.
During the baseline phase, 13 of 19 infants achieved success at $\leq 70 \mathrm{~ms}$ ISI on at least one type of stimuli; 9 of 13 were successful at $\leq 40 \mathrm{~ms}$ ISI on at least one type of stimulus.

PEx group-passive experience protocol. Sound exposure for the PEx group began 1 week after completion of the 4 month pretest session. Infants visited the laboratory once a week $(\sim 20 \mathrm{~min})$ for 6 consecutive weeks.

Stimuli for passive experience protocol. At each $20 \mathrm{~min}$ session, infants were passively exposed to exactly the same temporally modulated auditory sequences as used in the active condition, as follows: weeks 1 and 2: complex tones (STD, $800-800 \mathrm{~Hz}$; DEV, $800-1200 \mathrm{~Hz}$ ); weeks 3 and 4: bandpass noise (STD, 400-1900 Hz and 400-1900 Hz; DEV, 400-1900 $\mathrm{Hz}$ and $800-1900 \mathrm{~Hz}$ ); and weeks 5 and 6: simple sweeps STD: $1600-$ $1200 \mathrm{~Hz}$ and $1600-1200 \mathrm{~Hz}$; DEV, $1600-1200 \mathrm{~Hz}$ and $1200-1600 \mathrm{~Hz}$ ).

Procedure for passive experience. The infant sat comfortably in an infant seat placed on a chair equidistant between left and right speakers in a sound-attenuated and electrically shielded sound booth (Industrial Acoustics Company). The stimuli were presented free field while the infant was silently entertained with puppets/silent toys to maintain alertness. Two blocks of stimuli were presented in random order at each session, $10 \mathrm{~min}$ at $40 \mathrm{~ms}$ ISI and $10 \mathrm{~min}$ at $70 \mathrm{~ms}$ ISI. This condition was designed to increase spectrotemporal processing efficiency through controlled background exposure.

\section{Analytic strategy}

The focus of this study was to assess the efficacy of using an active experience protocol to induce changes in neural representation of auditory information and in auditory processing between 4 and 7 months of age. The analyses reported here focus on changes in the cortical electrophysiology of the infant, over and above typical maturation or passive experience alone, across the age period of interest. Independent-samples $t$ tests were conducted to assess typical maturational changes from 4 to 7 months of age. Preliminary analyses of the 4 month data were conducted to ensure that there were no systematic group differences between AEx and PEx groups at the initial visit. Figure $1 b$ shows the grand average waveforms for the 4-month-old children who were randomized into either the AEx or PEx groups as well as the grand average waveform for all of the 4-month-old children combined. As expected, $t$ tests comparing the two 4-month-old groups revealed no significant differences on any of the indices assessed in this study ( $t$ value range, 2.0 to $-2.0 ; p$ value range, $0.06-0.99)$, and thus the full 4 month sample was used for the crosssectional maturation analyses (i.e., comparison of 4 and 7 month EEG/ ERPs).

To measure the effects of auditory exposure over and above that of maturation, a series of ANOVA models was used to assess differences in ERP amplitude and latency by age (4 vs 7 months of age), group (AEx vs PEx vs NC), and stimulus type (STD vs DEV) for each condition ( $300 \mathrm{~ms}$ ISI, $70 \mathrm{~ms}$ ISI, and multideviant oddball). Bonferroni and Tukey-Kramer corrections were conducted for multiple comparisons.

\section{Results}

Cross-sectional analysis between 4- and 7-month-old infants: maturational effects on morphology, latency, and amplitude

The morphology, latency and amplitude of the 4-month-old NC group (who were naive at this first pretraining visit) was compared with that of the 7-month-old NC group (Fig. 1c, grand average waveforms for the 4- and 7-month-old NC groups). Results from independent-samples $t$ tests revealed maturational effects for both morphology and latency. For the $300 \mathrm{~ms}$ ISI tone pairs, at 4 months we see a four-peak response to the tone pair (P1, N1, and P2 followed by a large negativity between 400 and $500 \mathrm{~ms}$ ). At 7 months, a more clearly defined and well developed eight-peak response to the tone pair (tone 1: P1, N1, P2, and N2; tone 2: $\mathrm{P} 1_{\mathrm{T} 2}, \mathrm{~N}_{\mathrm{T} 2}, \mathrm{P} 2_{\mathrm{T} 2}$, and $\mathrm{N} 2_{\mathrm{T} 2}$ ) was observed on both standard and deviant waves at all sites examined (Fig. $1 c$; see Table 1 for specific time windows). Independent-samples $t$ tests of the positive peak responses to tone $1(\mathrm{P} 1, \mathrm{P} 2)$ revealed significantly 
faster latencies for the 7-month-old group compared with the younger infants (STD: $t_{(37)}$ range, $2.0-3.7$; DEV: $t_{(37)}$ range, $2.0-$ $4.3, p<0.05)$ and showed significantly larger amplitudes on the STD and DEV waves (STD: $t_{(37)}$ range, 2.1-2.2; DEV: $t_{(37)}$ range, $2.1-4.3, p<0.05)$.

For the $70 \mathrm{~ms}$ ISI tone pairs, there was a three-peak response at both 4 and 7 months on both standard waves (P1, N1, and P2) and deviant waves (P1, N2*, and P2; Fig. $1 b)$. $t$ Tests of the positive peaks on standard (P1) and deviant (P1, P2) waves at 7 months were significantly faster (STD: $t_{(44)}$ range, -4.3 to 5.5; DEV: $t_{(44)}$ range, $\left.2.1-4.5, p<0.04\right)$ and smaller in amplitude (STD: $t_{(44)}$ range, $2.1-5.0$; DEV: $t_{(44)}$ range, $2.4-3.2, p<0.05$ ) as compared with 4-month-old children. Negative peak amplitudes increased from 4 to 7 months for both STD and DEV waves (STD: $t_{(44)}$ range, 3.1-4.6; DEV: $t_{(44)}$ range, $\left.2.3-3.2, p<0.03\right)$.

\section{Group effects of auditory exposure on latency and amplitude beyond maturation}

We then examined differences among all three 7-month-old groups (i.e., AEx, PEx, and NC groups) to measure the effects of auditory exposure over and above maturational effects. Waveforms were inspected across the entire time period with a specific focus on the P2 and $\mathrm{N}^{*}$ components. Given the active versus passive experience contrast, we hypothesized that there might be a differential effect among groups on components that have been implicated in modulation of attention or vigilance. The P2 component is thought to reflect transient sensory-processing abilities (Ceponiene et al., 2001), specifically processes linked to stimulus awareness and perceptual salience (Ceponiene et al., 2005), and also has been suggested as an index of auditory recognition memory (deRegnier, 2007; Mai et al., 2012). The N2* component on the deviant wave is also of prime interest as it marks the beginning of the discrimination response and has been shown to be a robust infant predictor of later language outcomes (Benasich et al., 2006; Choudhury and Benasich, 2011).

The impact of interactive acoustic experience was found primarily for performance on the fast-rate stimuli (70 ms ISI), although significant effects of auditory exposure in favor of the AEx group were observed for the amplitude of the $\mathrm{P} 2$ component for both 300 and $70 \mathrm{~ms}$ ISI conditions. In the fast-rate condition (70 ms ISI), the P2 for the deviant wave also demonstrated significant latency effects. More importantly, significant latency and amplitude effects as a function of auditory exposure were shown for the $\mathrm{N} 2{ }^{*}$ on the deviant wave (Fig. $2 a$ depicts the overlaid waveforms for each of the three 7-month-old groups by condition).

\section{P2 amplitude at $300 \mathrm{~ms}$ ISI}

To assess group differences in $\mathrm{P} 2$ peak amplitude responses to the $800 \mathrm{~Hz}$ tones, a total of four $\mathrm{P} 2$ peaks (two peaks from the standard pair, one from the predeviant standard and the single peak from the target $1200 \mathrm{~Hz}$ tone) were examined with a 3 (group) $\times$ 4 (P2 peak amplitude) factorial ANOVA. While a main effect for the $1200 \mathrm{~Hz}$ tone revealed that all three groups had significantly larger $\mathrm{P} 2$ responses for the deviant tone (range, $F_{(3,105)}=4.4-$ 17.8; $p<0.006$ ), a significant interaction for frontal (range, $\left.F_{(6,105)}=2.3-2.7 ; p<0.04\right)$, frontocentral $\left(\right.$ range, $F_{(6,105)}=2.2-$ $2.7 ; p<0.05$ ), and central (range, $F_{(6,105)}=2.2-2.4 ; p<0.04$ ) channels was also found. The AEx group had significantly higher amplitude for the oft-repeated $800 \mathrm{~Hz}$ tones when compared with both the PEx and NC groups (Fig. 2b).

\section{P2 amplitude at $70 \mathrm{~ms} I S I$}

To examine this same effect in the $70 \mathrm{~ms}$ ISI condition, a 3 (group) $\times 2$ (P2 peak amplitude) ANOVA was run, as only two
P2 peaks were identified for this temporally modulated condition. Results showed a significant group difference for frontocentral channels $\left(F_{(2,46)}=3.7, p<0.03\right)$ and central channels $\left(F_{(2,46)}\right.$ range $=3.5-6.5 ; p<0.04)$. The NC group had significantly smaller amplitudes for both the $800 \mathrm{~Hz}$ (STD) and $1200 \mathrm{~Hz}$ (DEV) tones compared with those for the AEx and PEx groups (Fig. 2c).

\section{P2 latency and $\mathrm{N}^{\star}$ latency/amplitude at $70 \mathrm{~ms}$ ISI}

Further analysis using a one-way ANOVA revealed significant enhancement in the speed of acoustic processing. Specifically, the AEx group achieved significantly faster latencies $(\sim 40-50 \mathrm{~ms})$ for the $\mathrm{P} 2$ peak on the deviant wave (range, $F_{(2,46)}=3.4-8.9, p<$ 0.04 ) compared with both PEx and NC groups (Fig. $3 a$ ). For the $\mathrm{N} 2^{\star}$ on the deviant wave, the AEx and PEx groups showed significantly faster $(\sim 20-40 \mathrm{~ms})$ latencies (range, $F_{(2,46)}=3.6-4.2$, $p<0.04)$ than the NC group, and the AEx group showed larger amplitudes (range $F_{(2,46)}=3.4-6.0$ to $12, p<0.04$ ) compared with those for both the PEx and NC groups (Fig. 3b).

\section{Group effects of auditory exposure on morphology} beyond maturation

A prominent effect was also seen on ERP morphology for the AEx group. Specifically, additional negative and positive peaks emerged at 400 and $511 \mathrm{~ms}$, respectively, for the $70 \mathrm{~ms}$ ISI stimuli, creating a double-peaked waveform not observed consistently for either the PEx or NC groups (Fig. $4 a$, star). To investigate this further among all participants, we used a group-blind protocol; two independent raters visually inspected each individual's deviant waveform within a $250-550 \mathrm{~ms}$ window to verify the presence or absence of these additional peaks. A majority of infants in the AEx group (78\%) showed the presence of these double peaks, while they were present for only $41 \%$ of the passive group and $28 \%$ of the NC group $\left(\chi^{2}=8.6, p=0.01\right)$. Emergence of new peaks precedes development of more complex waveforms (Choudhury and Benasich, 2011). Thus, these emerging peaks at 7 months of age suggest accelerated development of more complex waveforms resembling those seen in typically developing 12 and 24-month-old infants (Choudhury and Benasich, 2011) without training (see examples in Fig. 4b). Please note that although the emergent peaks observed in 7-month-old children had similar topography to those in older children, these peaks were of the longer latency and larger amplitude typical of younger infants (Shafer et al., 2000; Kushnerenko et al., 2002; Sussman et al., 2008; Choudhury and Benasich, 2011).

Generalization to nonexposed stimuli in multideviant paradigm These results were not attributable to a specific and isolated "practice" effect. Significantly, these enhanced processing profiles generalized to new, different stimuli that the infants had not previously experienced, but were similar in acoustic structure, incorporating rapid spectrotemporal change as described in Materials and Methods. Thus, for this multideviant generalization condition, P1 and N1 peak amplitude and latency responses to the standard and three generalization stimuli (gap, duration, and frequency) were examined. A four-peak response was seen for the standard and each of the generalization deviants, and were labeled according to the following order of appearance: P1, N1, P2, and N2 (for analysis time windows, see Table 1). The N1 within this multideviant paradigm may or may not be the same discrimination-related response $\left(\mathrm{N} 2^{\star}\right)$ as seen for tone-paired stimuli. However, note that the N1 induced in the multideviant paradigm occurs in both standard and deviant waves at $\sim 200 \mathrm{~ms}$. Further, the discrimination response on the deviant waveform 

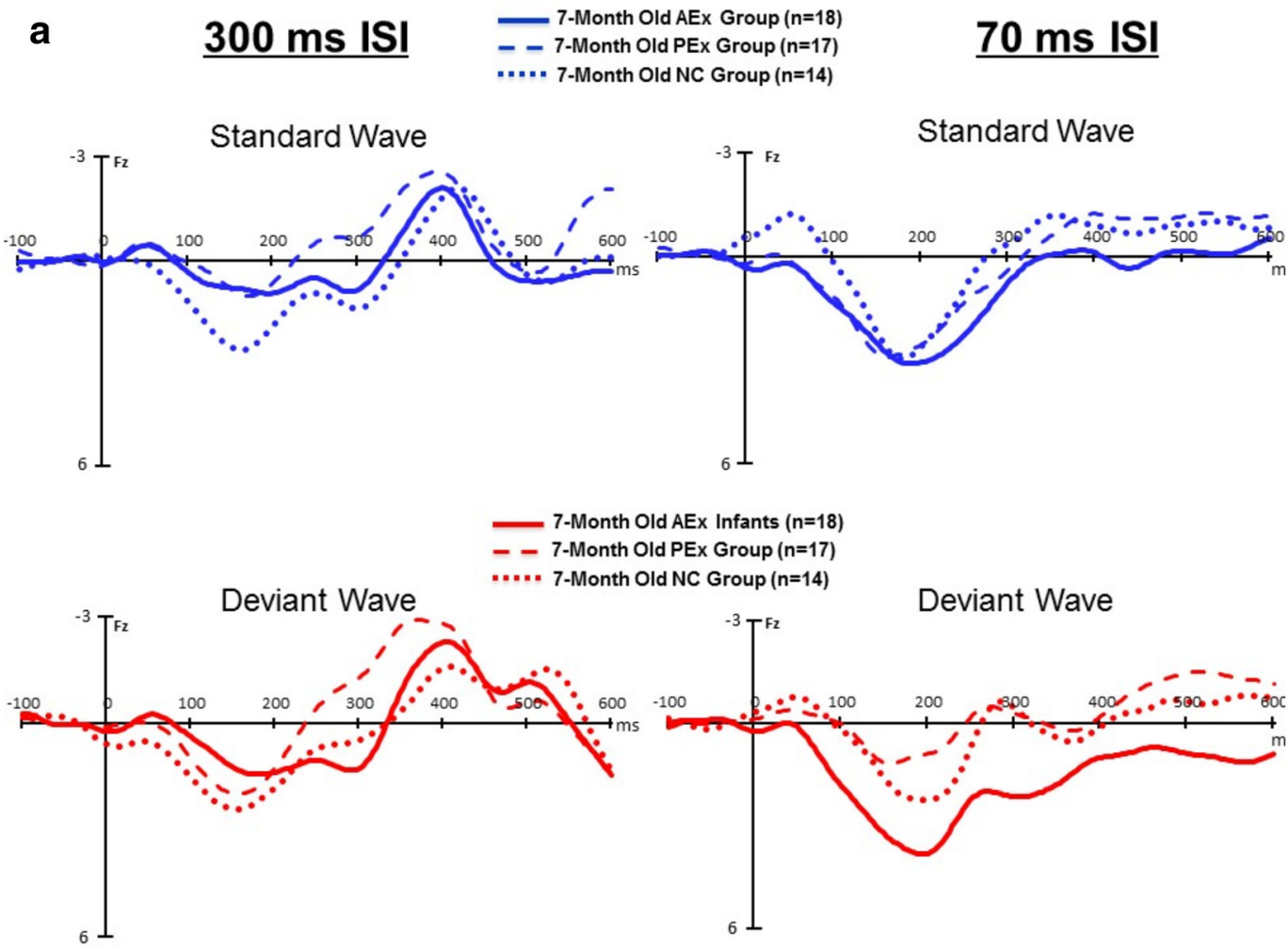

b

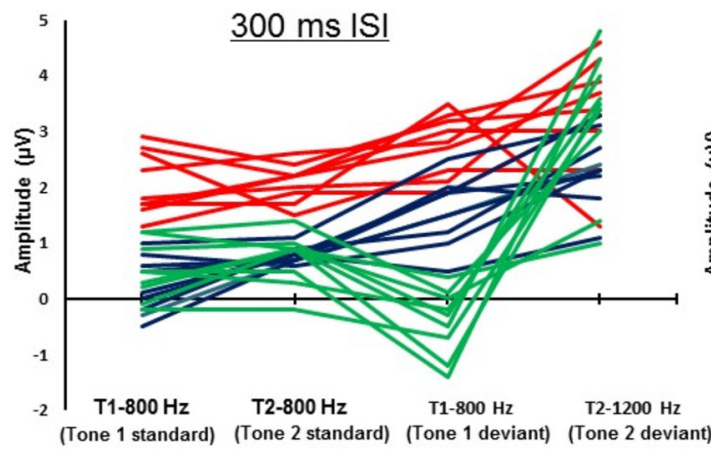

C

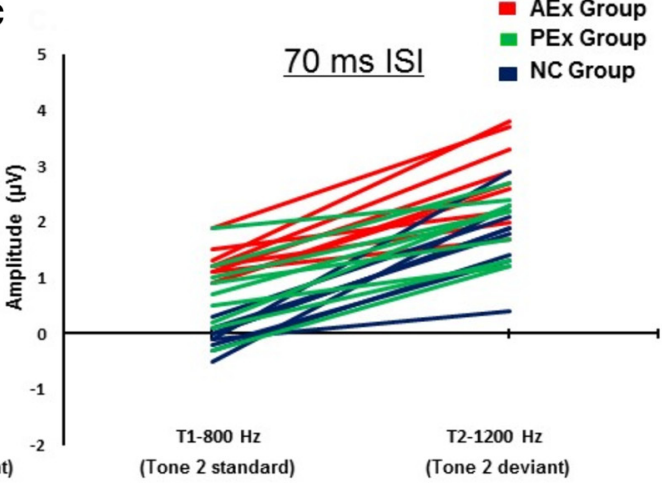

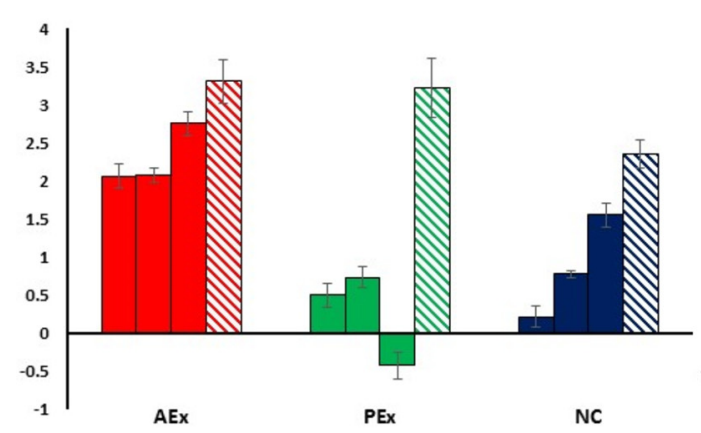

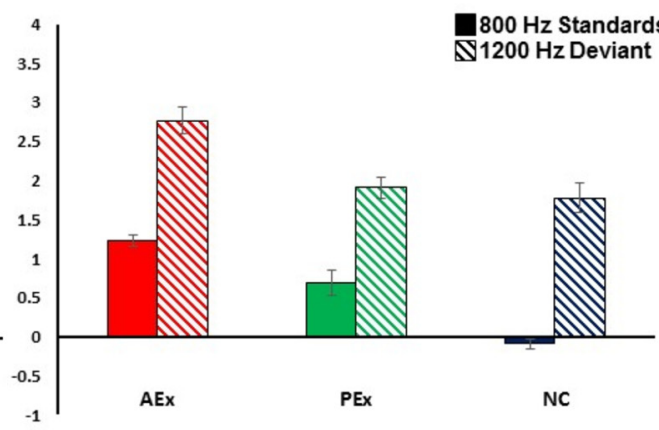

Figure 2. Group effects of auditory exposure on latency and amplitude for all three groups at the 7 month post-test. $\boldsymbol{a}$, Grand average waveforms from 124 electrodes overlaid for AEx (solid line), PEx (dashed line), and NC (dotted line) groups at Fz. Standard (blue) and deviant (red) waves are shown for the control ( $300 \mathrm{~ms} I S I)$ and fast-rate (70 ms ISI) conditions. $\boldsymbol{b}$, P2 peak amplitudes for all nine electrodes of interest are shown by group (red, AEx; green, PEx; blue, NC) for each tone of the two tone pairs in the $300 \mathrm{~ms} \mathrm{ISI} \mathrm{condition.} \mathrm{The} \mathrm{four} \mathrm{P2} \mathrm{peaks} \mathrm{depicted} \mathrm{on} \mathrm{the} x$-axis include the P2 responses to the standard pair (two) and from the predeviant standard (one), as well as the P2 peak elicited by the $1200 \mathrm{~Hz}$ deviant tone. The AEx group achieved significantly higher amplitudes for the repeated $800 \mathrm{~Hz}$ standard tones compared with the PEx and NC groups. However, all groups had significantly higher amplitudes for the $1200 \mathrm{~Hz}$ deviant tone. Bar graphs (error bars indicate SEM) show the mean P2 peak amplitude for each tone. T1, tone 1; T2, tone 2; solid bars, $800 \mathrm{~Hz}$ tones; striped bars, $1200 \mathrm{~Hz}$ tone. c, P2 peak amplitudes for all nine electrodes of interest by group (red, AEx; green, PEx; blue, NC) for each of the merged tone pairs in the $70 \mathrm{~ms}$ ISI condition. Only two P2 peaks are generated at $70 \mathrm{~ms}$ ISI. The NC group had significantly lower amplitudes for both the STD $(800-800 \mathrm{~Hz})$ and DEV $(800-1200 \mathrm{~Hz})$ merged tones compared with those in the AEx and PEx groups. Bar graphs (error bars indicate SEM) show the mean P2 peak amplitude for each tone. T1, Tone 1; T2, tone2; solid bars, STD; striped bars, DEV. 
a

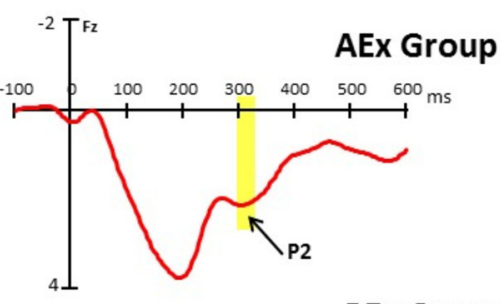

PEx Group
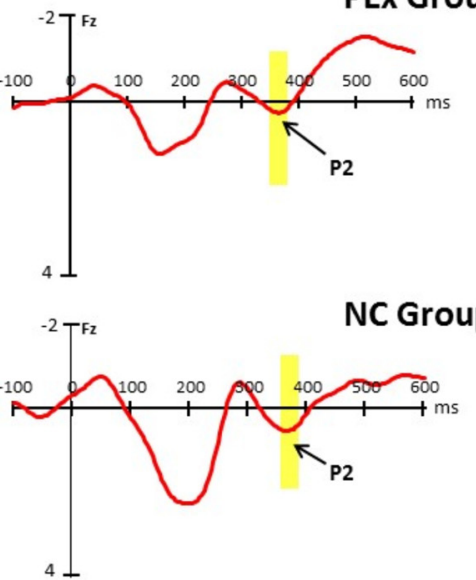
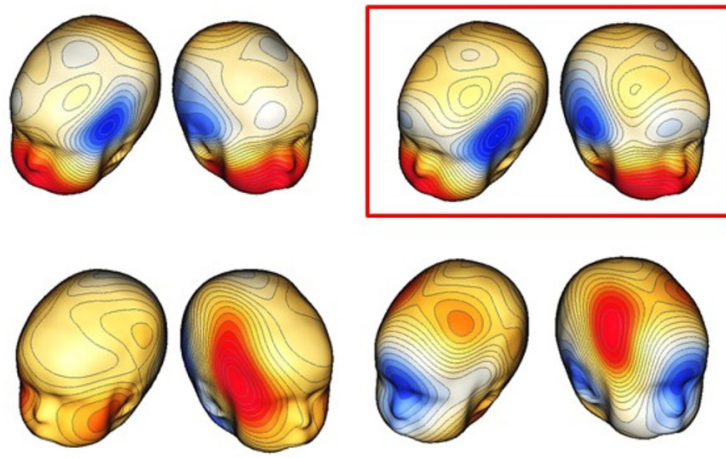

$340 \mathrm{~ms}$

L $\quad \mathbf{R}$
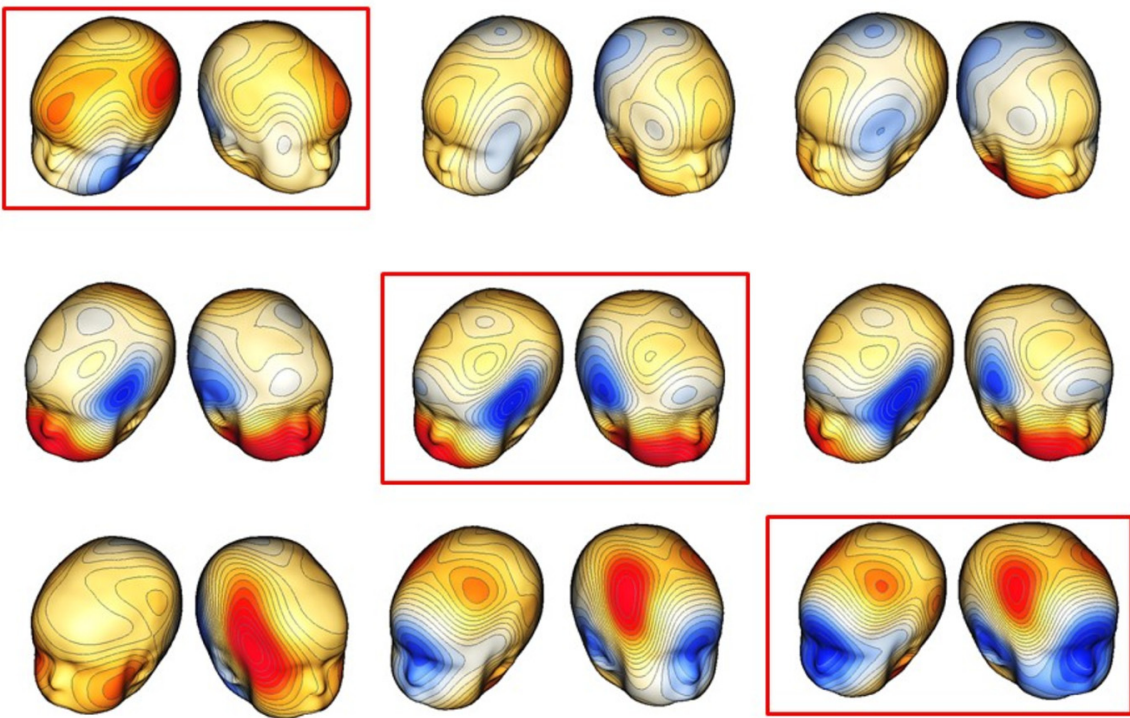

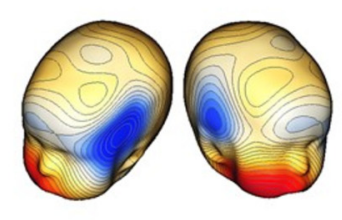

$360 \mathrm{~ms}$

L $\quad \mathbf{R}$

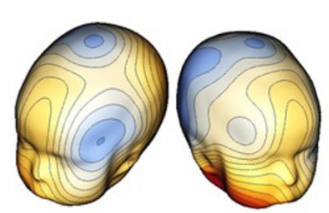

1.0
0.5
0.0
0.5
-0.0

b

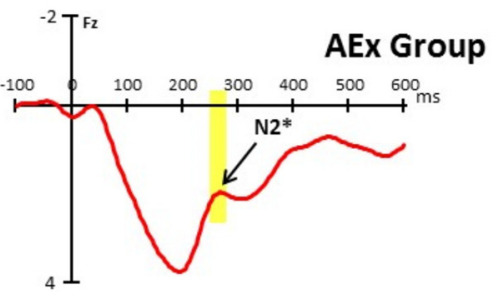

$264 \mathrm{~ms}$

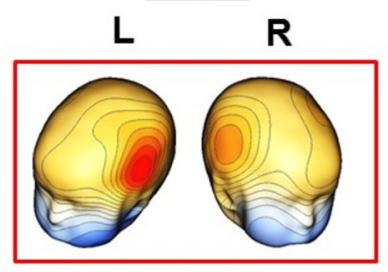

PEx Group
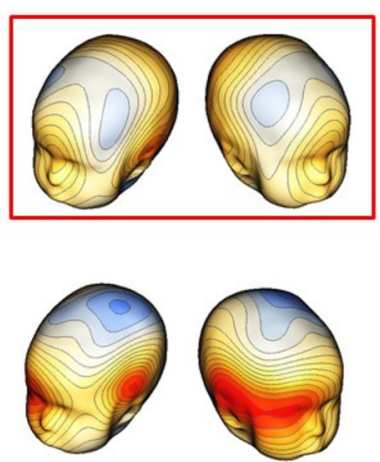

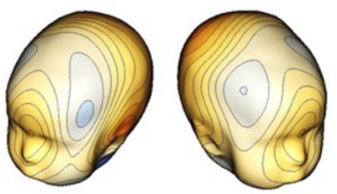

$\underline{284} \mathrm{~ms}$
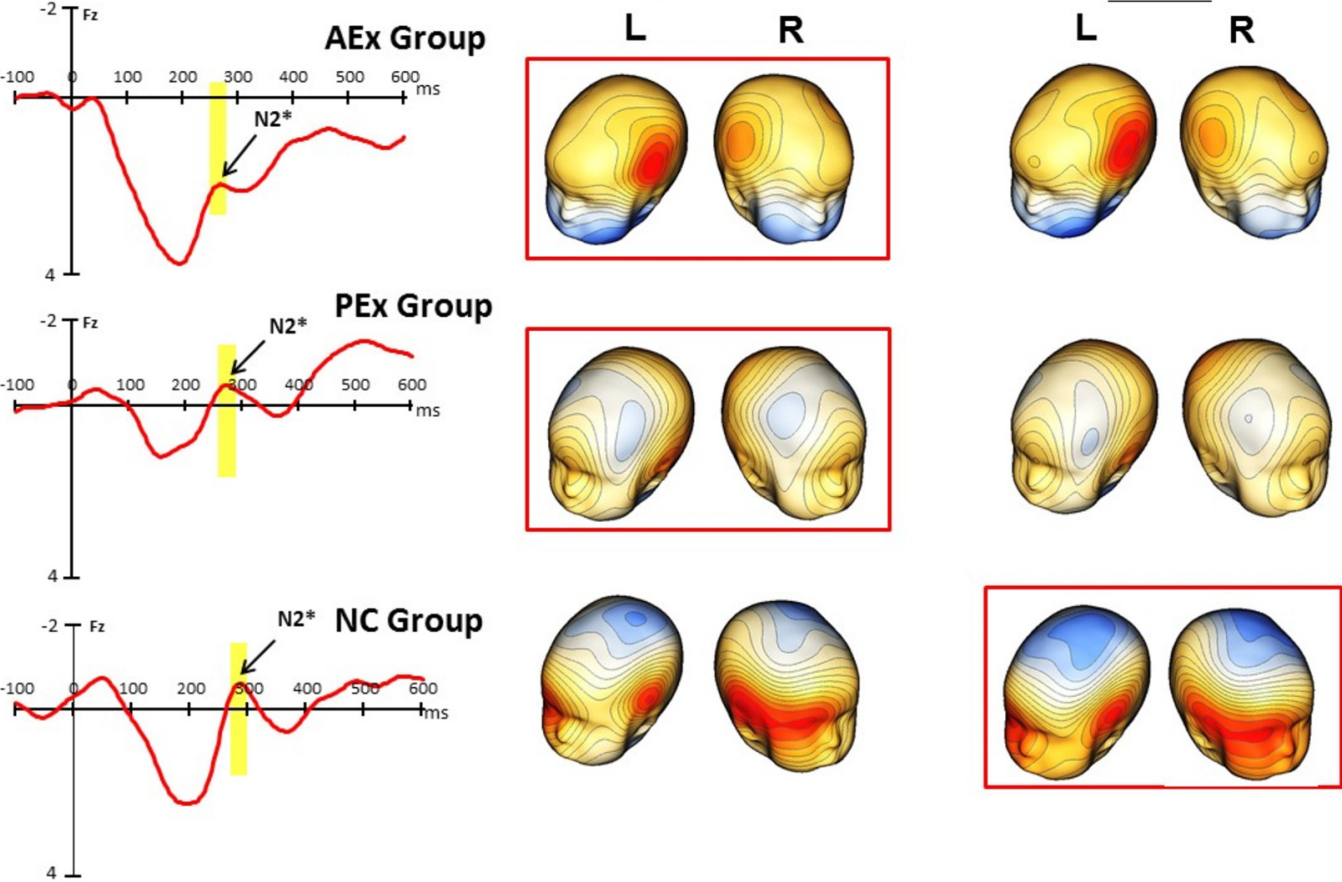

70 ms ISI Deviant N2* Peak Component

Figure 3. Group differences in latency and amplitude at $70 \mathrm{~ms} \mathrm{ISI}$ among the three groups at the 7 month post-test. $\boldsymbol{a}$, Grand average waveforms for all 124 electrodes by group are shown at $\mathrm{Fz}$ for the P2 peak on the deviant wave. Highlighted yellow bars on the deviant waveform indicate the location of the maximum P2 peak for each group. Time-locked, age-appropriate topograms to the P2 peak latency by group are also shown. The amplitude scale is shown in microvolts; blue represents negative and red positive activity. A red box around a topogram denotes significantly faster latencies. The AEx group is significantly faster than both the PEx and NC groups, and the PEx group is significantly faster than the NC group. $\boldsymbol{b}$, Grand average waveforms for all 124 electrodes by group are shown at $\mathrm{Fz}$ for the $\mathrm{N}^{*}$ on the deviant wave. Highlighted yellow bars on the deviant waveform indicate the location of the maximum N2* peak for each group. Time-locked, age-appropriate topograms to the $\mathrm{N}^{*}$ peak latency for each group are shown. Amplitude is in microvolts; blue represents negative and red positive activity. A red box around a topogram indicates significantly faster latencies. The AEx and the PEx groups are significantly faster than the NC group. 
a

\section{Representative Exemplar of AEx group}

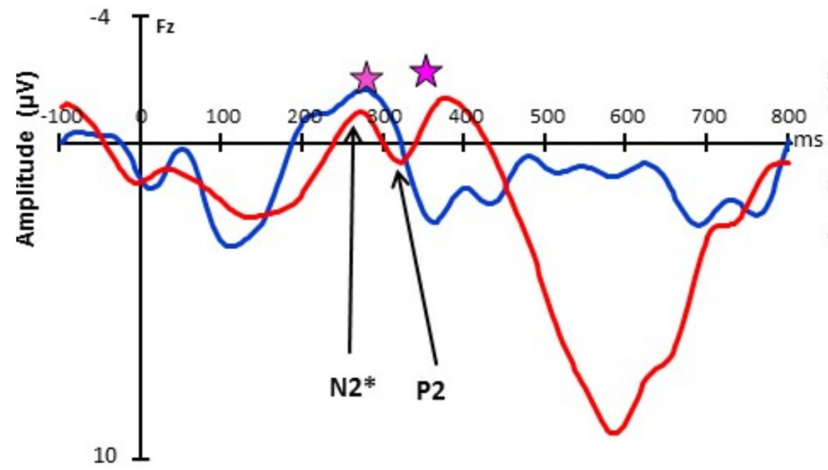

\section{Representative Exemplar of NC group}

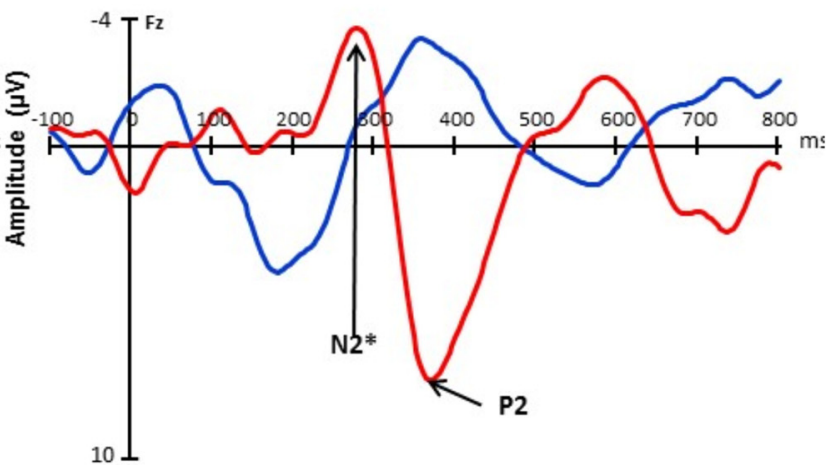

\section{Representative Exemplar of PEx group}

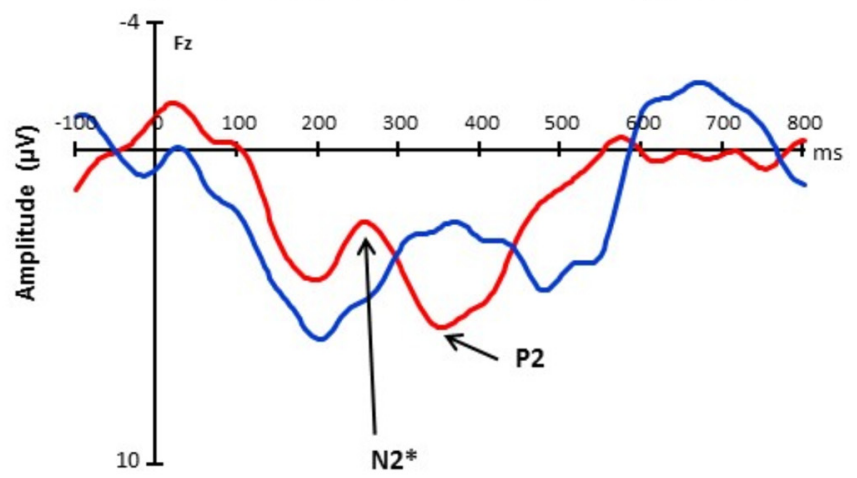

b
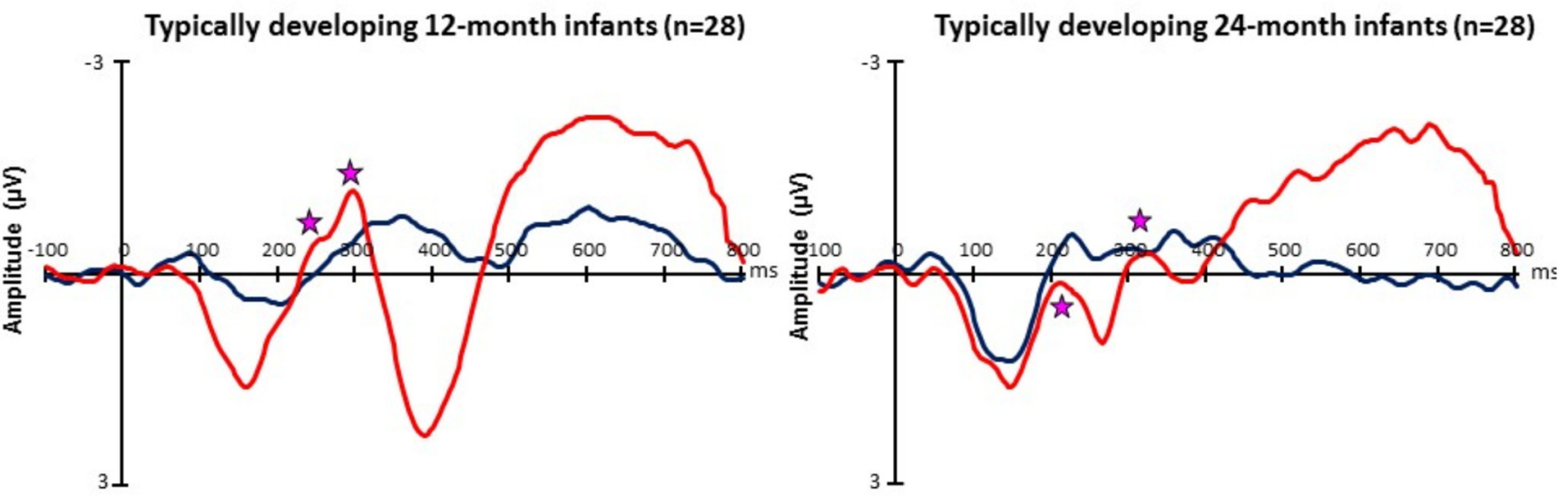

Figure 4. Group differences in morphology for the $70 \mathrm{~ms} \mathrm{ISI} \mathrm{grand} \mathrm{average} \mathrm{waveform} \mathrm{at} \mathrm{the} 7$ month post-test. $\boldsymbol{a}$, An exemplar waveform from each of the three 7-month-old groups demonstrates the emergence of additional peaks for the AEx group that are not evident for PEx or NC groups. Emerging double peaks (starred) were seen at the 7 month post-test in the majority (78\%) of AEx infants at 7 months of age; $41 \%$ of the PEx group and $22 \%$ of the NC group $\left(\chi^{2}=8.6, p=0.01\right.$ ) exhibited this signature maturational profile. $\boldsymbol{b}$, Morphologically similar double peaks (starred) seen in typically developing 12- and 24-month-old children. (Grand average waveforms at Fz were adapted from Choudhury and Benasich, 2011; plotted at slightly larger scale to accommodate larger-amplitude peaks of the younger infants.) While the double peaks depicted here for the older children are similar morphologically to those seen in the AEx group, typical maturational differences are present for these 12- and 24-month-old children, including faster latencies and smaller amplitudes are seen compared with the 7-month-old children in $\boldsymbol{a}$.

follows the N1 peak and at this point the groups differ significantly for the generalization deviants.

For the standard wave, a one-way ANOVA revealed that the AEx group had significantly faster latencies for the P1 peak component (range, $\left.F_{(2,34)}=4.4-7.7, p<0.05\right)$ and smaller, more mature amplitudes for the $\mathrm{P} 1$ and $\mathrm{N} 1$ peaks $\left(\mathrm{P} 1\right.$ : range, $F_{(2,34)}=$ $3.5-6.3$; N1: range, $\left.F_{(2,34)}=3.2-6.5, p<0.05\right)$. Moreover, the morphology for the standard waveform differed markedly between groups at every time point across the waveform. Figure $5 a$ shows the waveforms by group, and the bar graphs (Fig. 5b) 
a

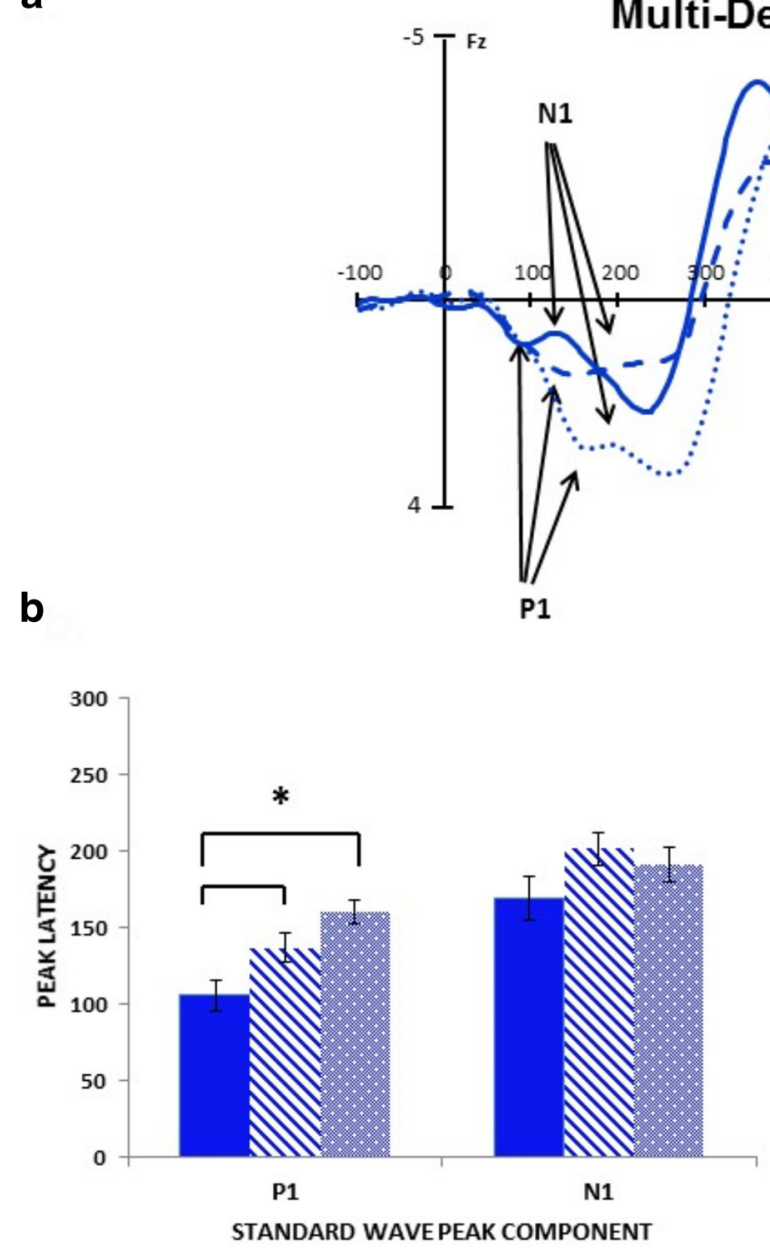

7-Month Old AEx Group ( $n=14)$

- - 7-Month Old PEx Group ( $n=12$ )

.... 7-Month Old NC Group ( $n=10)$
7- Month Old AEx Group ( $n=14)$

nv 7-Month Old PEx Group ( $n=12$ )

7-Month Old NC Group ( $n=10)$

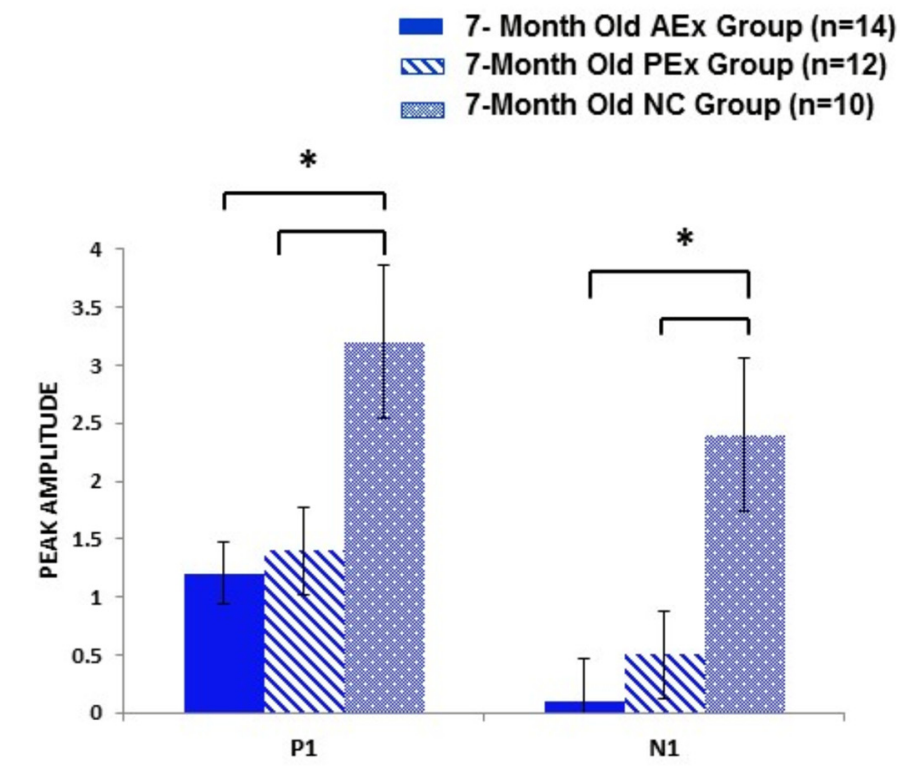

Figure 5. Generalization to nonexposed stimuli in the multideviant paradigm by group at the 7 month post-test: enhanced processing on the standard wave. $\boldsymbol{a}$, Grand average waveforms for all 124 electrodes at Fz by group to the STD stimulus in the multideviant generalization paradigm. The P1 peak for the STD waveform is significantly faster for the AEx group (solid line) than for the PEx (dashed line) and NC (dotted line) groups. $\boldsymbol{b}$, Bar graphs (error bars indicate SEM) depicting significantly faster latency of P1 for the STD in the multideviant generalization paradigm for the AEx group (left) when compared with PEx and NC groups. The AEx group also demonstrated smaller, more mature amplitudes for the P1 and N1 peaks compared with those in the PEx and NC groups. All values are plotted from the mean grand averages at $\mathrm{Fz}$.

illustrate the significant latency and amplitude differences for the $\mathrm{P} 1$ and $\mathrm{N} 1$ components.

For the deviant waves, a 3 (group) $\times 3$ (P1 peak to each deviant) factorial ANOVA revealed significant group differences for all frontal (range, $F_{(2,34)}=4.2-5.7, p<0.01$ ), frontocentral (range, $F_{(2,34)}=5.3-6.2, p<0.01$ ), and central channels (range, $\left.F_{(2,34)}=3.8-6.9, p<0.01\right)$ for P1 latency only (Fig. $6 a$ ). That is, the AEx group had significantly faster latencies for all three deviants on the P1 peak compared with both the PEx and NC groups. Similar to the P1, analysis of the N1 component showed significant interactions for latency at frontal (range, $F_{(4,68)}=2.8, p<$ 0.03 ), frontocentral (range, $F_{(4,68)}=3.0 ; p<0.03$ ), and central channels (range, $F_{(4,68)}=3.0-3.4, p<0.05$ ). Overall, while the mean latency of the $\mathrm{N} 1$ for all three deviants for the AEx group was faster than that for the PEx and NC groups, the interaction is a result of the $\mathrm{NC}$ group being notably slower when processing the frequency deviant (Fig. 6b). No significant amplitude differences were observed for P1 or N1 of the deviant waveform.

\section{Responses to the gap deviant}

As a specific example, we include here a more detailed analysis of the grand average waveform by group for the "gap" generaliza- tion deviant. This deviant stimulus in the multideviant paradigm required infants to make a challenging acoustic discrimination (detecting a $20 \mathrm{~ms}$ gap within a $70 \mathrm{~ms}$ tone) and also differed the most from the training stimulus set.

\section{Gap separation analysis}

As described above, the AEx infants achieved significantly faster P1 latencies for all generalization stimuli, including the gap deviant compared with both PEx and NC groups (Fig. 6a). Further examination of the gap deviant grand average waveforms by group also suggested that the AEx group was processing the deviant quite differently, as evidenced by the distribution of the P2-N2 complex (Fig. 7). These marked differences in morphology were of particular interest given that the 250 to $550 \mathrm{~ms}$ window of interest for this P2-N2 complex maps onto the time window in which the mismatch response (MMR) on the difference wave can be identified in this age group (i.e., $\sim 250-500 \mathrm{~ms}$ ) in 70 ms ISI conditions (Choudhury and Benasich, 2011) and thus seems to index deviant stimulus discrimination.

To investigate this further, using a group-blind protocol, each individual infant's deviant waveform was visually in- 
a

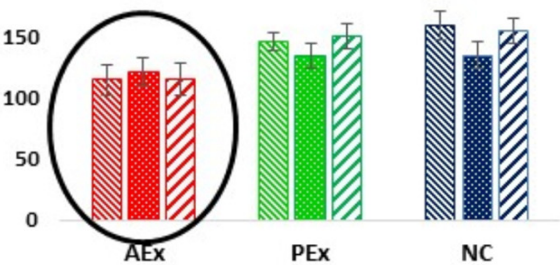

$F_{c 4}$

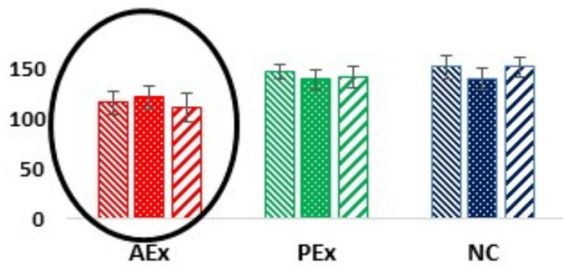

$\mathrm{C}_{3}$

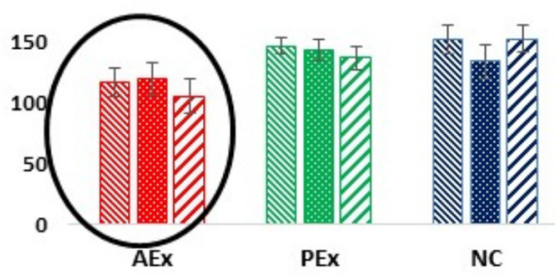

$\mathbb{Q}$ Gap Deviant Duration Deviant ZFrequency Deviant

$\mathrm{F}_{4}$

$F_{z}$

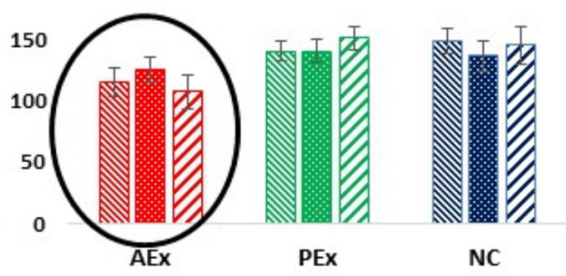

PEX

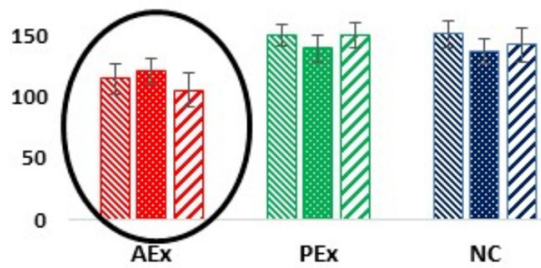

$F_{c z}$

$\mathbf{F}_{04}$

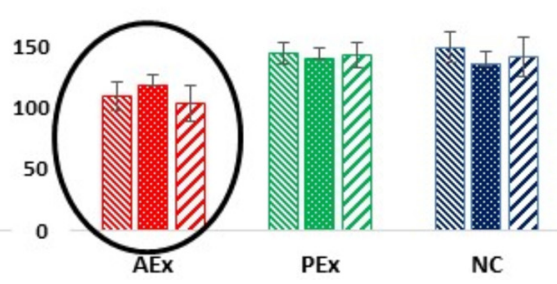

$\mathrm{C}_{\mathrm{z}}$

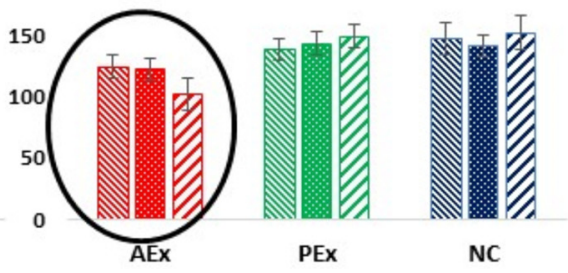

$\mathrm{C}_{4}$
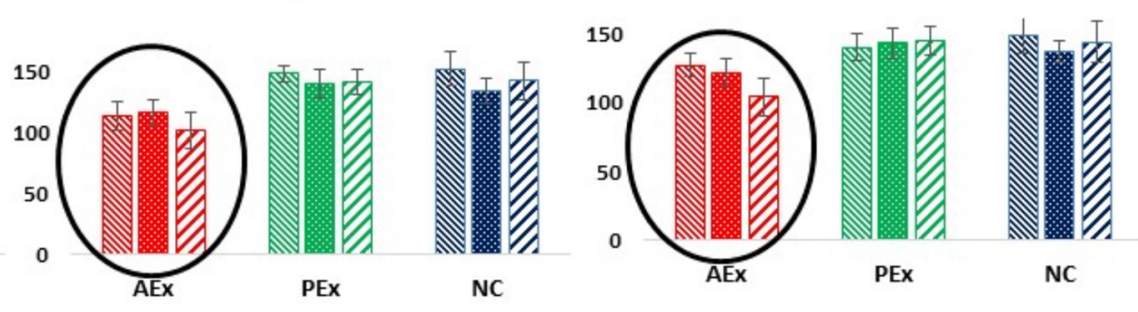

$\mathrm{O}=$ Sig group differences $p<.05$

b

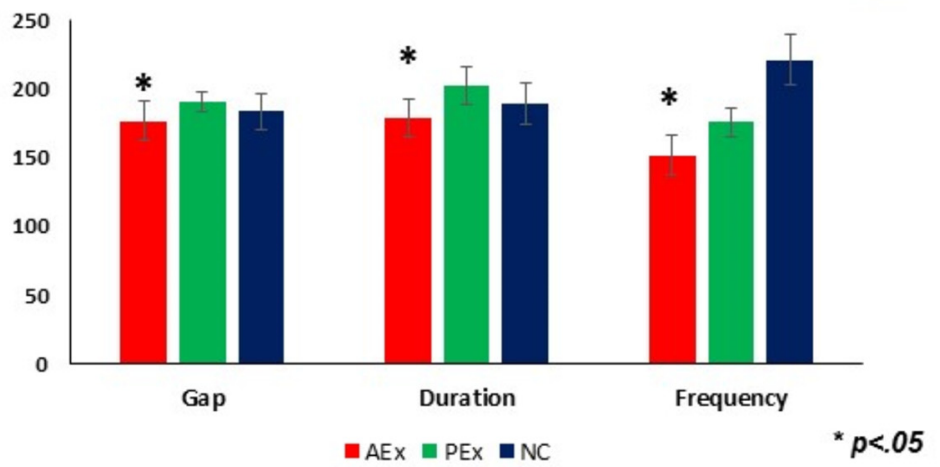

Figure 6. Generalization to nonexposed stimuli in the multideviant paradigm by group at the 7 month post-test: enhanced processing on P1 and N1 for all three deviants. $\boldsymbol{a}$, Bar graphs depict the mean latency of each DEV at each of the nine electrode sites by group. Significantly faster P1 latencies $(p<0.05)$ are seen for the AEx group (red) for all three deviants and for all nine electrode sites compared with those in the PEx (green) and NC (blue) groups. Significant differences are circled. $\boldsymbol{b}$, Bar graphs (error bars indicate SEM) show the mean latency of each group by DEV type (gap, duration, frequency). There were significant group interactions for N1 latency. For each deviant, the AEx group was significantly faster at all electrode sites than the PEx and NC groups ( $p$ values $<0.05$ ). A significant interaction revealed that the NC group was significantly slower when processing the frequency deviant. All values are plotted from the mean grand averages at $\mathrm{F} 3$. 

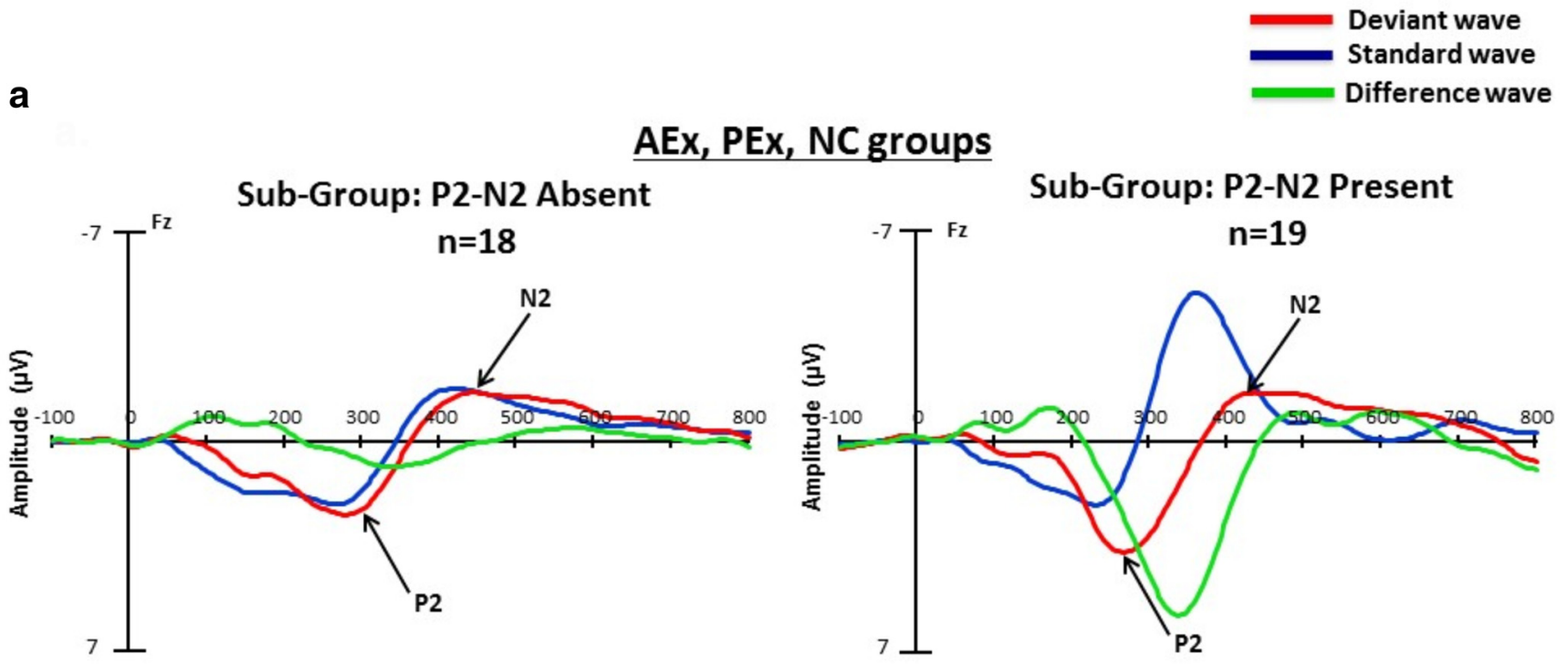

b

AEx \& NC groups
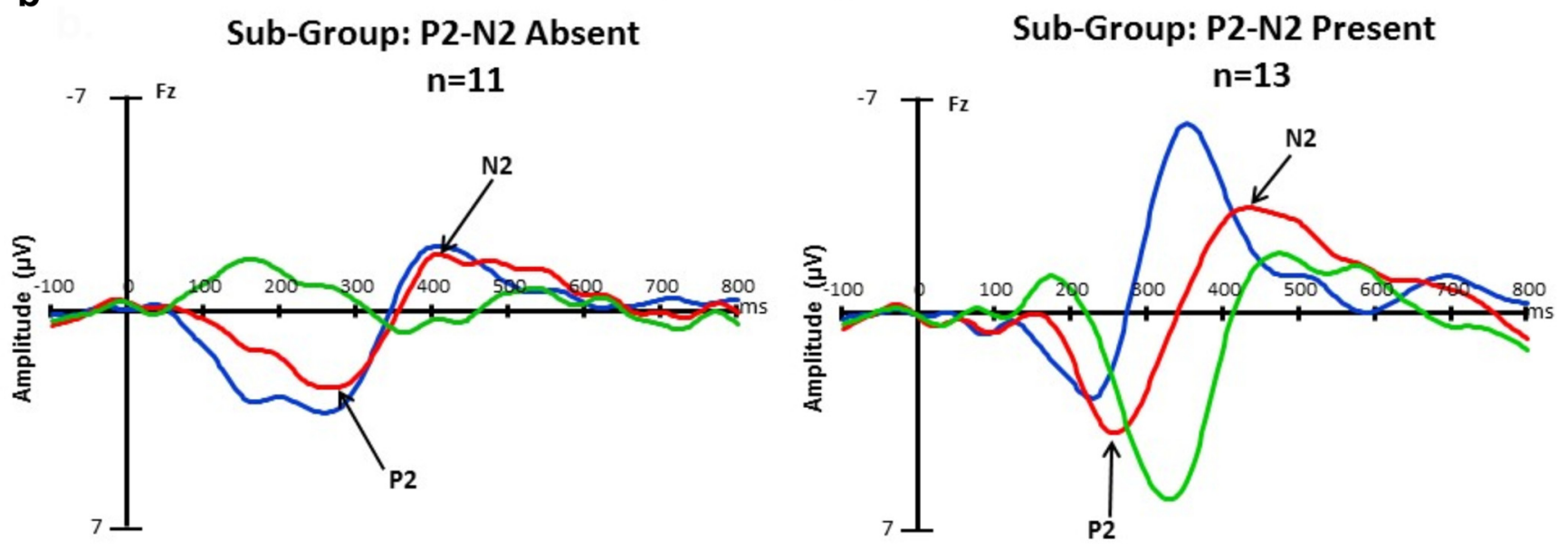

Figure 7. Generalization to nonexposed stimuli in the multideviant paradigm at the 7 month post-test: subgroup differences in the P2-N2 complex on the gap deviant. $\boldsymbol{a}$, Grand average waveforms for 124 electrodes at Fz to the gap generalization stimulus for all three groups (AEx, PEx, and NC) combined, sorted by P2-N2 subgroup (presence/absence of a P2-N2 complex in the $250-550 \mathrm{~ms}$ window). Standard (blue), deviant (red), and difference (green) waves are shown for the gap deviant stimulus. A P2-N2 complex was identified in 71\% of the AEx group, 41\% of the PEx, and $30 \%$ of the NC infants. The AEx group significantly differed from the NC group $(\chi 2=4.0, p<0.05)$; the PEx and NC groups did not differ from each other $(\chi 2=1.8, p=0.18) . \boldsymbol{b}$, Grand average waveforms for 124 electrodes at Fz to the gap generalization stimulus for two groups ( $A$ Ex and NC) combined, sorted by P2-N2 subgroup (absence of P2-N2 vs presence of P2-N2). Standard (blue), deviant (red), and difference (green) waves are shown for the gap deviant stimulus. Significant interactions were seen for all nine electrode sites examined (range, $F_{(1,20)}=5.2-10.8, p<$ 0.03 ). Infants in the AEx group who showed the P2-N2 complex had significantly faster latencies and showed better discrimination (i.e., significantly larger mismatch response amplitudes) when compared with those infants who did not show the P2-N2 complex (range, $F_{(1,20)}=5.2-16, p<0.03$ ).

spected by two independent raters and then sorted into two subgroups based on the $\mathrm{P} 2-\mathrm{N} 2$ complex distribution on the difference wave (presence/absence of a P2-N2 complex in the 250-550 ms window; Fig. 7a.) A majority of infants in the AEx group (71\%) showed this P2-N2 complex as indexed by a peak in the difference wave at 300-400 ms. In contrast, only $41 \%$ of the PEx and $30 \%$ of the NC infants generated similar topographies.

A series of $\chi^{2}$ analyses were computed to investigate how passive and active experience compared with no exposure influenced P2-N2 topography. Results revealed that the AEx group significantly differed from the NC group $\left(\chi^{2}=4.0, p<0.05\right)$, while there was no difference between the PEx and NC group. $\left(\chi^{2}=\right.$ $1.8, p=0.18)$. To follow up on these significant $\chi^{2}$ results, a 2 (group) $\times 2$ (subgroup) ANOVA for N2 peak amplitude and latency was used to examine AEx versus NC group differences (Fig. 7b). Significant interactions were seen for all nine sites examined (range, $F_{(1,20)}=5.2-10.8, p<0.03$ ). In all cases, infants in the AEx group that showed the P2-N2 complex achieved significantly faster latencies compared with their naive peers. No significant amplitude differences were found.

Similarly, a $2 \times 2$ ANOVA for the MMR from the difference wave was used to examine latency and amplitude differences between the two subgroups (Fig. 7b). Results revealed that infants that showed the P2-N2 complex had significantly larger amplitudes for the MMR compared with those infants who did not show the P2-N2 complex (range, $F_{(1,20)}=5.2-16, p<0.03$ ). All significant results are summarized in Table 2. 
Table 2. Summary table of results

\begin{tabular}{|c|c|c|c|c|c|}
\hline & Condition & Independent variables & Dependent variables & Test & Results \\
\hline \multirow{5}{*}{$\begin{array}{l}\text { Maturation: } \\
\text { cross-sectional }\end{array}$} & $300 \mathrm{~ms}$ ISI tone pair & 4- and 7-month-old cross- & 4 months: P1, N1, P2, N2 & Independent $t$ test & Significantly faster and larger P1 to tone 1 \\
\hline & & sectional age groups & $\begin{array}{l}7 \text { months: } \mathrm{P} 1, \mathrm{~N} 1, \mathrm{P} 2, \mathrm{~N} 2 \text { (to } \\
\text { tone 1); } \mathrm{P}_{\mathrm{T} 2}, \mathrm{~N}_{\mathrm{T} 2}, \mathrm{P}_{\mathrm{T} 2} \text {, } \\
\mathrm{N}_{\mathrm{T} 2} \text {, (to tone 2) }\end{array}$ & & $\begin{array}{l}\text { response for 7-month-old group } \\
\text { compared with younger group }\end{array}$ \\
\hline & $70 \mathrm{~ms}$ ISI tone pair & $\begin{array}{l}\text { 4- and 7-month-old cross- } \\
\text { sectional age groups }\end{array}$ & 4 and 7 months: P1, N1, P2 & Independent $t$ test & $\begin{array}{l}\text { Significantly faster and smaller P1 and P2 } \\
\text { responses for 7-month-old group }\end{array}$ \\
\hline & & & & & compared with younger group \\
\hline & & & & & $\begin{array}{l}\text { Significantly bigger negative peaks for } \\
\text { 7-month-old children }\end{array}$ \\
\hline \multicolumn{6}{|l|}{ Group differences } \\
\hline \multirow{5}{*}{$\begin{array}{l}\text { Amplitude and } \\
\text { latency differ- } \\
\text { ences }\end{array}$} & $300 \mathrm{~ms}$ ISI tone pair & $\begin{array}{l}\text { 7-month-old AEx, PEx, and NC } \\
\text { groups }\end{array}$ & $\begin{array}{l}\text { Four } \mathrm{P} 2 \text { peaks ( } 2 \text { from the } \\
\text { standard pair, } 1 \text { from the }\end{array}$ & $\begin{array}{l}3 \times 4 \text { factorial } \\
\text { ANOVA }\end{array}$ & $\begin{array}{l}\text { Significantly larger } P 2 \text { response for the } \\
\text { deviant tone }(1200 \mathrm{~Hz}) \text { for all } 3 \text { groups }\end{array}$ \\
\hline & & & $\begin{array}{l}\text { pre-deviant standard and } 1 \\
\text { from the deviant tone of the } \\
\text { target pair) }\end{array}$ & & $\begin{array}{l}\text { The AEX group had significantly bigger P2 } \\
\text { responses for the oft-repeated } 800 \mathrm{~Hz} \\
\text { tone }\end{array}$ \\
\hline & 70 ms ISI tone pair & $\begin{array}{l}\text { 7-month-old AEx, PEx, and NC } \\
\text { groups }\end{array}$ & $\begin{array}{l}\text { Two } P 2 \text { peaks ( } 1 \text { from standard } \\
\text { and } 1 \text { from deviant tone) }\end{array}$ & $\begin{array}{l}3 \times 2 \text { factorial } \\
\text { ANOVA }\end{array}$ & $\begin{array}{l}\text { Significantly smaller } P 2 \text { responses for the } \\
\text { NC group compared with the AEx and } \\
\text { PEx groups }\end{array}$ \\
\hline & $70 \mathrm{~ms}$ ISI tone pair & $\begin{array}{l}\text { 7-month-old AEx, PEx, and NC } \\
\text { groups }\end{array}$ & $\begin{array}{l}\mathrm{N} 2 * \text { and } \mathrm{P} 2 \text { peaks of deviant } \\
\text { wave }\end{array}$ & One-way ANOVA & $\begin{array}{l}\text { The AEx and PEx groups have significantly } \\
\text { faster } N 2^{*} \text { and } P 2 \text { responses }\end{array}$ \\
\hline & & & & & $\begin{array}{l}\text { The AEx group had significantly larger N2* } \\
\text { peak responses }\end{array}$ \\
\hline $\begin{array}{c}\text { Morphological } \\
\text { differences }\end{array}$ & $70 \mathrm{~ms}$ ISI tone pair & $\begin{array}{l}\text { 7-month-old AEx, PEx, and NC } \\
\text { groups }\end{array}$ & $\begin{array}{l}\text { Presence vs absence of new } \\
\text { emerging peaks }\end{array}$ & $\chi^{2}$ & $\begin{array}{l}\text { A majority of infants in the AEx group } \\
\text { showed the presence of emerging } \\
\text { peaks }\end{array}$ \\
\hline \multicolumn{6}{|l|}{ Generalization } \\
\hline \multirow[t]{3}{*}{$\begin{array}{c}\text { Multideviant } \\
\text { paradigm }\end{array}$} & Multideviant paradigm & $\begin{array}{l}\text { 7-month-old AEx, PEx, and NC } \\
\text { groups }\end{array}$ & $\begin{array}{l}\text { P1 and N1 peaks of the } \\
\text { standard wave }\end{array}$ & One-way ANOVA & $\begin{array}{l}\text { The AEx group had significantly faster } \mathrm{P} 1 \\
\text { peak responses and more mature } \mathrm{P} 1 \\
\text { and } \mathrm{N} 1 \text { responses }\end{array}$ \\
\hline & Multideviant paradigm & $\begin{array}{l}\text { 7-month-old AEx, PEx, and NC } \\
\text { groups }\end{array}$ & $\begin{array}{l}\text { P1 and N1 peaks for the } 3 \\
\text { deviants }\end{array}$ & $\begin{array}{c}3 \times 3 \text { factorial } \\
\text { ANOVA }\end{array}$ & $\begin{array}{l}\text { The AEx group had significantly faster } \mathrm{P} 1 \\
\text { peak responses }\end{array}$ \\
\hline & & & & & $\begin{array}{l}\text { Significant interactions for } \mathrm{N} 1 \text { peak } \\
\text { responses where the NC group was } \\
\text { notably slower compared to the other } \\
\text { two groups }\end{array}$ \\
\hline \multirow[t]{4}{*}{ Gap deviant } & Gap deviant of multideviant & AEx group vs NC group & Presence vs Absence of P2-N2 & $\chi^{2}$ & The AEx group significantly differed from \\
\hline & paradigm & PEx group vs NC group & complex & & $\begin{array}{l}\text { the NC group while there was no } \\
\text { significant difference between PEx and } \\
\text { NC groups }\end{array}$ \\
\hline & $\begin{array}{l}\text { Gap deviant of multideviant } \\
\text { paradigm }\end{array}$ & $\begin{array}{l}\text { Group (AEx vs NC) vs subgroup } \\
\text { (presence of P2-N2 complex vs } \\
\text { absence of P2-N2 complex) }\end{array}$ & N2 peak response & $2 \times 2$ ANOVA & $\begin{array}{l}\text { Significant interactions found where the } \\
\text { AEx group that showed the P2-N2 } \\
\text { complex had faster latencies as } \\
\text { compared to their naive peers }\end{array}$ \\
\hline & $\begin{array}{l}\text { Gap deviant of multi-deviant } \\
\text { paradigm }\end{array}$ & $\begin{array}{l}\text { Group (AEx vs NC) vs subgroup } \\
\text { (presence of P2-N2 complexvs } \\
\text { absence of P2-N2 complex) }\end{array}$ & MMR (mismatch response) & $2 \times 2$ ANOVA & $\begin{array}{l}\text { Infants that showed the P2-N2 complex } \\
\text { had significantly larger MMR responses } \\
\text { compared with those infants who did } \\
\text { not show the P2-N2 complex }\end{array}$ \\
\hline
\end{tabular}

\section{Discussion}

In this study, we demonstrate that both active and passive acoustic experience from 4 to 7 months of age, using temporally modulated nonspeech stimuli, impacts acoustic processing. However, progressive active experience that recruits attention confers a significant advantage, producing specific and measurable changes in the morphology, amplitude, and latency of brain waves that are surrogates for prelinguistic acoustic mapping. The data show qualitative as well as quantitative changes. In particular, we observed significant effects of active acoustic experience on the accuracy and speed of discrimination of key prelinguistic acoustic cues. These effects are over and above that seen for passive exposure or maturation alone. Response to fast-rate stimuli (with tens-of-milliseconds "speech-like" timing) more effectively im- pacted EEG surrogates for acoustic mapping. Alterations in waveform morphology for the multideviant standard stimulus in the generalization paradigm were seen most prominently in the AEx group, suggesting a more clearly defined and accessible stimulus representation (Näätänen and Winkler, 1999; Polley et al., 2006; Schreiner and Winer, 2007). Finally, infants who had acoustic exposure generalized an enhanced processing profile to multiple novel temporally modulated stimuli. The AEx group demonstrated significantly faster P1 latencies for all three generalization stimuli compared with the PEx and NC groups. Moreover, examination of the P2-N2 complex on the challenging gap deviant suggests that the AEx group is generating a larger-amplitude $\mathrm{MMR}$, an ERP marker for the construction of stimulus-feature representations in auditory sensory memory (Näätänen, 2001). 
We suggest, given the similarity to findings in the animal literature, that both active and passive training induce sharpening of automatic acoustic processing, perhaps bootstrapping and fine tuning the creation of well defined acoustic maps (Kilgard et al., 2001; Schreiner and Winer, 2007; Woods et al., 2009). Another candidate and probably convergent mechanism for the AEx group may be improved allocation of attentional resources (Kauramäki et al., 2007; Schreiner and Winer, 2007) during mapping. The significant amplitude differences seen for the AEx group on the P2 peak might be interpreted as an early attention/ vigilance effect that signals involuntary allocation of attention toward an environmental stimulus (Escera et al., 2000), reflecting increased levels of "perceptual vigilance" (Ortiz-Mantilla et al., 2010). Although some facilitation of acoustic mapping was seen in the PEx group, a greater effect was observed in the AEx infants. Attention/vigilance, even at this early age, may confer a substantial advantage. It has also been shown in adults that focusing attention on salient information drives neural dynamics and that selective attention increases both gain and feature selectivity of the human auditory cortex (Kauramäki et al., 2007; Woods et al., 2009).

Given the many animal studies that demonstrate continuous modification of developing cortical representations by the sensory environment (Kilgard et al., 2001; Woods et al., 2009; Froemke and Jones, 2011), we believe that the changes seen here may be a manifestation of sound exposure-based plasticity that is typical of this early developmental period. The human neocortex is particularly attentive to statistically distributed acoustic cues during early critical periods, when cortical networks are organizing around salient features of the sensory environment (Saffran et al., 1996; Maye et al., 2002). Precisely targeted nonlinguistic acoustic experience that focuses the infant's attention on linguistically relevant environmental cues may facilitate neural plasticity in this early developmental period (Kauramäki et al., 2007; Kuhl, 2010; Reed et al., 2011; Ranasinghe et al., 2012). Thus, we used nonlinguistic acoustic cues to provide a universal, less languagespecific input and to facilitate generalization, while minimizing perceptual-narrowing effects.

For the AEx infants, significantly faster and more precise responses to both familiar and novel stimuli, as measured by ERPs, were elicited compared with naive age-matched control subjects. The PEx group showed significant enhancement in processing speed in several analyses compared with the NC group. However, the PEx group never outperformed the AEx infants and often did not differ from the NC group. Morphology of the waveforms is also seen to reflect a more mature topography, with the emergence of waveform complexity in the AEx infants. Although these morphological profiles look similar to those generated by older children, they are also age appropriate in important ways, including larger amplitude and slower latencies typically seen when comparing younger to older children.

Comparison of before and after profiles illustrates a more "optimal processing profile" for the AEx infants, based on published results of longitudinal predictive studies and maturational profiles of EEG/ERP (Guttorm et al., 2005; Benasich et al., 2006; Choudhury and Benasich, 2011). Components most favorably altered include the $\mathrm{P} 1, \mathrm{P} 2$, and $\mathrm{N} 2{ }^{*}$. The $\mathrm{N} 2{ }^{*}$ has been the best predictor of linguistic outcome from the infancy period through 4 years of age (Benasich et al., 2006; Choudhury and Benasich, 2011). Across previous studies, children who demonstrated infant electrophysiological profiles similar to that shown by the AEx group were most likely to later show superior standardized language outcomes, whereas those with longer $\mathrm{N} 2 *$ latencies and more immature topography had significantly poorer language outcomes (Benasich et al., 2006; Choudhury and Benasich, 2011).

As noted above and shown in Figure 5, $a$ and $b$, the morphology of the multideviant standard also differed between the age-matched 7-month-old groups at every point across the waveform, including the $\mathrm{P} 1$ and $\mathrm{N} 1$ peaks. Repetition of the standard stimulus induces a neural representation of the stimulus reiterations, extracted from the acoustic signal, which is then maintained in auditory memory, providing a basis for continuous comparisons with subsequent acoustic input. Formation of this memory trace or "sensory map" is critical as it allows efficient discrimination of subsequent deviant stimuli. Our finding that the AEx infants can more quickly and efficiently process the multideviant standard implies that active experience generates a "more accessible" representation and further suggests that interactive auditory experience induced experience-dependent changes in sensory memory (Näätänen and Winkler, 1999; Benasich et al., 2006; Polley et al., 2006).

The ability of the brain to decode incoming speech is dependent upon the accurate perception of rapid acoustic changes (Eimas et al., 1971; Jusczyk et al., 1980; Kraus et al., 1996; Benasich and Tallal, 2002). Both the precision of biological encoding of sound and the "stability" of the neural representation throughout the auditory system are important contributors to accurate acoustic mapping (Banai et al., 2009; Hornickel et al., 2009; Hornickel and Kraus, 2013; Centanni et al., 2014). Difficulties in biological encoding can result in distorted neural boundaries, unstable representation of sound, and degraded categorical and phonemic representations (Werker and Tees, 1987; Tallal, 2000; Hornickel et al., 2012; Centanni et al., 2014). Such unstable and perhaps overinclusive representations lead to difficulty in decoding and identifying speech as well as nonspeech transitions in the domain of tens of milliseconds that is highly associated with language impairments in older children and adults (Kraus et al., 1996; Tallal, 2004; McArthur and Bishop, 2005; Oram Cardy et al., 2005; Hornickel et al., 2009; Hornickel et al., 2012).

In previous studies, we have shown that the ability to accurately process such rapid acoustic change can be reliably assessed in infancy, and that infant nonlinguistic acoustic processing abilities predict robustly to later language (Benasich and Tallal, 2002; Benasich et al., 2006; Choudhury and Benasich, 2011). Thus, we believe that the results reported here have significant implications for typical as well as atypical language development. As hypothesized, only faster-rate stimuli elicited widespread and significant changes in ERPs compared with the naive control group. This may reflect plasticity in response mechanisms for phonemic characteristics that share the same temporal resolution, such as consonant-vowel transitions. However, a number of animal studies have also shown a rate-specific effect as a result of acoustic exposure and experience (Threlkeld et al., 2009; de Villers-Sidani et al., 2010), so these results need further exploration.

This study was tightly focused on the impact of experience on acoustic processing/mapping; however, there is much still to be accomplished in this domain. Although the effects seen here are quite robust, limitations included a relatively small sample and infants that were screened to exclude those at familial risk for language learning impairment (LLI). Thus, an important next step will be to recruit a much larger sample of typically developing children and to include those at higher risk for LLI. As we follow this sample longitudinally, we also hope to investigate the ongoing impact of active auditory experience on EEG/ERP as well as subsequent language and cognitive outcomes. Moreover, it will be 
important to examine additional longitudinal manipulations using other modalities (e.g., visual, auditory-visual) as well as the impact of individual differences on response to auditory experience.

In summary, active exposure during early infancy to nonspeech stimuli containing linguistically relevant acoustic cues appears to confer a significant acoustic processing advantage when compared with passive exposure or maturation alone. Specifically, such experience appears to facilitate neural plasticity and more efficient sensory processing during the developmental period when infants are constructing their sensory maps. Further exploration of experience-dependent neural mechanisms underlying acoustic mapping will provide the opportunity to identify and characterize the earliest precursors and biological markers of normative and disordered language processing. Precisely targeted support of emergent plasticity in acoustic mapping for infants at higher risk for language disorders as a function of a positive family history may provide a new and powerful avenue for amelioration and perhaps prevention of such disorders.

\section{References}

Aslin RN (1989) Discrimination of frequency transitions by human infants. J Acoust Soc Am 86:582-590. CrossRef Medline

Banai K, Hornickel J, Skoe E, Nicol T, Zecker S, Kraus N (2009) Reading and subcortical auditory function. Cereb Cortex 19:2699-2707. CrossRef Medline

Benasich AA, Tallal P (2002) Infant discrimination of rapid auditory cues predicts later language impairment. Behav Brain Res 136:31-49. CrossRef Medline

Benasich AA, Choudhury N, Friedman JT, Realpe-Bonilla T, Chojnowska C, Gou Z (2006) The infant as a prelinguistic model for language learning impairments: predicting from event-related potentials to behavior. Neuropsychology 44:396-411. CrossRef

Centanni TM, Booker AB, Sloan AM, Chen F, Maher BJ, Carraway RS, Khodaparast N, Rennaker R, LoTurco JJ, Kilgard MP (2014) Knockdown of the dyslexia-associated gene kiaa0319 impairs temporal responses to speech stimuli in rat primary auditory cortex. Cereb Cortex 24:17531766. CrossRef Medline

Ceponiene R, Shestakova A, Balan P, Alku P, Yiaguchi K, Näätänen R (2001) Children's auditory event-related potentials index sound complexity and "speechness". Int J Neurosci 109:245-260. Medline

Ceponiene R, Alku P, Westerfield M, Torki M, Townsend J (2005) ERPs differentiate syllable and nonphonetic sound processing in children and adults. Psychophysiology 42:391-406. CrossRef Medline

Cheour M, Martynova O, Näätänen R, Erkkola R, Sillanpää M, Kero P, Raz A, Kaipio ML, Hiltunen J, Aaltonen O, Savela J, Hämäläinen H (2002) Psychobiology: speech sounds learned by sleeping newborns. Nature 415: 599-600. CrossRef Medline

Choudhury N, Benasich AA (2011) Maturation of auditory evoked potentials from 6 to 48 months: prediction to 3- and 4-year language and cognitive abilities. Clin Neurophysiol 122:320-338. CrossRef Medline

deRegnier RA, Long JD, Georgieff MK, Nelson CA (2007) Using eventrelated potentials to study perinatal nutrition and brain development in infants of diabetic mothers. Dev Neuropsychol 31:379-396. CrossRef Medline

de Villers-Sidani E, Chang EF, Bao S, Merzenich MM (2007) Critical period window for spectral tuning defined in the primary auditory cortex (A1) in the rat. J Neurosci 27:180-189. CrossRef Medline

de Villers-Sidani E, Alzghoul L, Zhou X, Simpson KL, Lin RC, Merzenich MM (2010) Recovery of functional and structural age-related changes in the rat primary auditory cortex with operant training. Proc Natl Acad Sci U S A 107:13900-13905. CrossRef Medline

Eilers RE, Morse PA, Gavin WJ, Oller DK (1981) Discrimination of voice onset time in infancy. J Acoust Soc Am 70:955-965. CrossRef Medline

Eimas PD, Siqueland ER, Jusczyk P, Vigorito J (1971) Speech perception in infants. Science 171:303-306. CrossRef Medline

Escera C, Alho K, Schröger E, Winkler I (2000) Involuntary attention and distractibility as evaluated with event-related brain potentials. Audiol Neurootol 5:151-166. CrossRef Medline

Froemke RC, Jones BJ (2011) Development of auditory cortical synaptic receptive fields. Neurosci Biobehav Rev 35:2105-2113. CrossRef Medline
Guenther FH, Gjaja MN (1996) The perceptual magnet effect as an emergent property of neural map formation. J Acoust Soc Am 100:1111-1121. CrossRef Medline

Guttorm TK, Leppänen PH, Poikkeus AM, Eklund KM, Lyytinen P, Lyytinen H (2005) Brain event-related potentials (ERPs) measured at birth predict later language development in children with and without familial risk for dyslexia. Cortex 41:291-303. CrossRef Medline

Hornickel J, Kraus N (2013) Unstable representation of sound: a biological marker of dyslexia. J Neurosci 33:3500-3504. CrossRef Medline

Hornickel J, Skoe E, Nicol T, Zecker S, Kraus N (2009) Subcortical differentiation of stop consonants relates to reading and speech-in-noise perception. Proc Natl Acad Sci U S A 106:13022-13027. CrossRef Medline

Hornickel J, Zecker SG, Bradlow AR, Kraus N (2012) Assistive listening devices drive neuroplasticity in children with dyslexia. Proc Natl Acad Sci U S A 109:16731-16736. CrossRef Medline

Jusczyk PW, Pisoni DB, Walley A, Murray J (1980) Discrimination of relative onset time of two-component tones by infants. J Acoust Soc Am 67:262-270. CrossRef Medline

Kauramäki J, Jääskeläinen IP, Sams M (2007) Selective attention increases both gain and feature selectivity of the human auditory cortex. PLoS One 2:e909. CrossRef Medline

Kilgard MP, Pandya PK, Vazquez J, Gehi A, Schreiner CE, Merzenich MM (2001) Sensory input directs spatial and temporal plasticity in primary auditory cortex. J Neurophysiol 86:326-338. Medline

Kraus N, McGee TJ, Carrell TD, Zecker SG, Nicol TG, Koch DB (1996) Auditory neurophysiologic responses and discrimination deficits in children with learning problems. Science 273:971-973. CrossRef Medline

Kuhl PK (2010) Brain mechanisms in early language acquisition. Neuron 67:713-727. CrossRef Medline

Kuhl PK, Williams KA, Lacerda F, Stevens KN, Lindblom B (1992) Linguistic experience alters phonetic perception in infants by 6 months of age. Science 255:606-608. CrossRef Medline

Kuhl PK, Tsao FM, Liu HM (2003) Foreign-language experience in infancy: effects of short-term exposure and social interaction on phonetic learning. Proc Natl Acad Sci U S A 100:9096-9101. CrossRef Medline

Kushnerenko E, Ceponiene R, Balan P, Fellman V, Huotilaine M, Näätäne R (2002) Maturation of the auditory event-related potentials during the first year of life. Neuroreport 13:47-51. CrossRef Medline

Mai X, Xu L, Li M, Shao J, Zhao Z, deRegnier RA, Nelson CA, Lozoff B (2012) Auditory recognition memory in 2-month-old infants as assessed by event-related potentials. Dev Neuropsychol 37:400-414. CrossRef Medline

Maye J, Werker JF, Gerken L (2002) Infant sensitivity to distributional information can affect phonetic discrimination. Cognition 82:B101-B111. CrossRef Medline

McArthur GM, Bishop DV (2005) Speech and non-speech processing in people with specific language impairment: a behavioural and electrophysiological study. Brain Lang 94:260-273. CrossRef Medline

Moucha R, Pandya PK, Engineer ND, Rathbun DL, Kilgard MP (2005) Background sounds contribute to spectrotemporal plasticity in primary auditory cortex. Exp Brain Res 162:417-427. CrossRef Medline

Näätänen R (2001) The perception of speech sounds by the human brain as reflected by the mismatch negativity (MMN) and its magnetic equivalent (MMNm). Psychophysiology 38:1-21. CrossRef Medline

Näätänen R, Winkler I (1999) The concept of auditory stimulus representation in cognitive neuroscience. Psychol Bull 125:826-859. CrossRef Medline

Nawyn J, Roesler C, Realpe-Bonilla T, Choudhury N, Benasich AA (2007) An operantly conditioned looking task for assessing infant auditory processing ability. Paper presented at the 9th International ACM SIGACCESS Conference on Computers and Accessibility, Tempe, AZ, October.

Oram Cardy JE, Flagg EJ, Roberts W, Brian J, Roberts TP (2005) Magnetoencephalography identifies rapid temporal processing deficit in autism and language impairment. Neuroreport 16:329-332. CrossRef Medline

Ortiz-Mantilla S, Choudhury N, Alvarez B, Benasich AA (2010) Involuntary switching of attention mediates differences in event-related responses to complex tones between early and late Spanish-English bilinguals. Brain Res 1362:78-92. CrossRef Medline

Polley DB, Steinberg EE, Merzenich MM (2006) Perceptual learning directs auditory cortical map reorganization through top-down influences. J Neurosci 26:4970-4982. CrossRef Medline 
Ranasinghe KG, Carraway RS, Borland MS, Moreno NA, Hanacik EA, Miller RS, Kilgard MP (2012) Speech discrimination after early exposure to pulsed-noise or speech. Hear Res 289:1-12. CrossRef Medline

Reed A, Riley J, Carraway R, Carrasco A, Perez C, Jakkamsetti V, Kilgard MP (2011) Cortical map plasticity improves learning but is not necessary for improved performance. Neuron 70:121-131. CrossRef Medline

Saffran JR, Aslin RN, Newport EL (1996) Statistical learning by eightmonth old infants. Science 274:1926-1928. CrossRef Medline

Schreiner CE, Winer JA (2007) Auditory cortex mapmaking: principles, projections, and plasticity. Neuron 56:356-365. CrossRef Medline

Shafer VL, Morr ML, Kreuzer JA, Kurtzberg D (2000) Maturation of mismatch negativity in school-age children. Ear Hear 21:242-251. CrossRef Medline

Sussman E, Steinschneider M, Gumenyuka V, Grushko J, Lawson K (2008) The maturation of human evoked brain potentials to sounds presented at different stimulus rates. Hear Res 236:61-79. CrossRef Medline

Tallal P (2000) The science of literacy: from the laboratory to the classroom. Proc Natl Acad Sci U S A 97:2402-2404. CrossRef Medline

Tallal P (2004) Improving language and literacy is a matter of time. Nat Rev Neurosci 5:721-728. CrossRef Medline

Threlkeld SW, Hill CA, Rosen GD, Fitch RH (2009) Early acoustic discrimination experience ameliorates auditory processing deficits in male rats with cortical developmental disruption. Int J Dev Neurosci 27:321-328. CrossRef Medline

Trainor LJ, Lee K, Bosnyak DJ (2011) Cortical plasticity in 4-month-old infants: specific effects of experience with musical timbres. Brain Topogr 24:192-203. CrossRef Medline

Trehub SE, Bull D, Schneider BA, Morrongiello BA (1986) PESTI: a procedure for estimating individual thresholds in infant listeners. Infant Behav Dev 9:107-118. CrossRef

Werker JF, Tees RC (1987) Speech perception in severely disabled and average reading children. Can J Psychol 41:48-61. CrossRef Medline

Werker JF, Tees RC (2005) Speech perception as a window for understanding plasticity and commitment in language systems of the brain. Dev Psychobiol 46:233-251. CrossRef Medline

Woods DL, Stecker GC, Rinne T, Herron TJ, Cate AD, Yund EW, Liao I, Kang X (2009) Functional maps of human auditory cortex: effects of acoustic features and attention. PLoS One 4:e5183. CrossRef Medline

Zhang LI, Bao S, Merzenich MM (2001) Persistent and specific influences of early acoustic environments on primary auditory cortex. Nat Neurosci 4:1123-1130. CrossRef Medline

Zhang LI, Bao S, Merzenich MM (2002) Disruption of primary auditory cortex by synchronous auditory inputs during a critical period. Proc Natl Acad Sci U S A 99:2309-2314. CrossRef Medline 